\title{
A Reappraisal of the Allocation Puzzle through the Portfolio Approach *
}

\author{
Kenza Benhima ${ }^{\ddagger}$ \\ UNIVERSITY OF LAUSANNE
}

May 10, 2012

\begin{abstract}
Paradoxically, high-growth, high-investment developing countries tend to experience capital outflows. This paper shows that this allocation puzzle can be explained simply by introducing uninsurable idiosyncratic investment risk in the neoclassical growth model with international trade in bonds, and by taking into account not only TFP catch-up, but also the capital wedge, that is, the distortions on the return to capital. The model fits the two following facts, documented on a sample of 67 countries between 1980 and 2003: (i) TFP growth is positively correlated with capital outflows in a sample including creditor countries; (ii) the long-run level of capital per efficient unit of labor is positively correlated with capital outflows. Consistently, we show that the capital flows predicted by the model are positively correlated with the actual ones in this sample once the capital wedge is accounted for. The fact that Asia dominates global imbalances can be explained by its relatively low capital wedge.
\end{abstract}

Key Words: Capital flows, Global imbalances, Investment risk.

JEL Class.: F36, F41, F43.

*Part of this research has been carried out within the project on "Macro Risk, systemic risks and international finance" (A2) of the National Centre of Competence in Research "Financial Valuation and Risk Management" (NCCR FINRISK). The NCCR FINRISK is a research instrument of the Swiss National Science Foundation.

$\dagger$ I acknowledge the help of two anonymous referees and the Editor. I would like to thank Mark Aguiar, Philippe Bacchetta, Agnès Bénassy-Quéré, Nicolas Berman, Daniel Cohen, Jean Imbs, Imen Ghattassi, Pierre-Olivier Gourinchas, Sebnem Kalemli-Özcan, Guy Laroque, Philippe Martin, Baptiste Massenot, Valérie Mignon, Romain Rancière and Hélène Rey for helpful comments. I also thank seminar participants at Banque de France, CREST, GREQAM, Paris School of Economics, the University of Lausanne, the University of Le Mans, the University of Evry, the European Economic Association 2009 (Barcelona), Theories and Methods of Macroeconomics (T2M) 2009 (Strasbourg), Research in International Economics and Finance 2009 (Aix-Marseille) and the North American Winter Meeting of the Econometic Society 2010 (Atlanta).

${ }^{\ddagger}$ University of Lausanne, UNIL-Dorigny, Extranef, room 250, 1015 Lausanne. TEL: $(+41)(0)$ 21.692.36.92. Email: Kenza.Benhima@unil.ch 


\section{Introduction}

Empirical studies on capital flows to developing countries suggest that the predictions of the neoclassical growth model (Ramsey-Cass-Koopmans) are not verified in the data. This model predicts that capital should flow to countries with high growth and high investment rates, both to finance investment and to help households smooth consumption. However, the opposite seems to hold in reality: Aizenman and Pinto (2007) and Prasad et al. (2007) established that capital flows to countries with low growth and low investment rates. Consequently, as Gourinchas and Jeanne (2009) show, capital outflows predicted by the neoclassical model are negatively correlated with actual outflows. Providing an explanation to this "puzzle" is the objective of this paper. Explaining the allocation puzzle would also help understand the phenomenon of global imbalances, and especially their structure. In particular, why are surpluses originated in Asia and not in Latin America or Africa? Indeed, Asia has experienced relatively high growth and high investment rates and should have imported capital instead of exporting it.

Because the growth accounting literature attributes a large share of growth differences to productivity, Gourinchas and Jeanne focus on TFP growth as the main driver of capital flows. ${ }^{1}$ However, as shown by Figure 1, which represents cross-country correlations between 1980 and 2003 in a sample of developing countries, investment is more robustly correlated with current account balances than growth in output per worker. Because growth in output per worker is mostly driven by TFP growth, this suggests that TFP growth cannot be the main source of the allocation puzzle. Although TFP growth also explains investment differences between countries, other factors, such as distortions due to institutional failures like expropriation risk, or the relative price of capital are also a non-negligible source of investment differences. ${ }^{2}$ All these factors amount to a "capital wedge", that is, to a discrepancy between the private and social return to capital. We argue that taking into account differences in this capital wedge is crucial to explain the allocation puzzle.

Theoretically, this paper provides a framework that can generate a positive longrun correlation between investment and capital outflows and gives the conditions and channels through which such a correlation emerges. This framework simply involves an extension of the neoclassical growth model that accounts for uninsurable idiosyncratic investment risk and international trade in bonds. Importantly, it also incorporates the two main drivers of growth and investment, that is TFP growth, which is the focus of Gourinchas and Jeanne, but also the capital wedge. More precisely, we show (i) that capital outflows are positively correlated with TFP catch-up only for countries with positive steady-state external positions; (ii) that capital outflows are negatively correlated with the capital wedge, and that this negative relationship survives in countries with negative steady-state external positions. This makes the capital wedge a more likely

\footnotetext{
${ }^{1}$ See Hall and Jones (1999) and Caselli (2004).

${ }^{2}$ see Caselli and Feyrer (2007) and Hsieh and Klenow (2007).
} 
source of the allocation puzzle. Empirically, using a sample of 67 developing countries between 1980 and 2003, we show that the capital flows predicted by the model are positively correlated with the actual ones once the capital wedge is accounted for. We also use the model to analyze the origins of global imbalances.

The long-run relationship between capital outflows and TFP growth, namely, the fact that it depends on the sign of the external position, is driven by a portfolio growth effect. In the presence of risk, the long-run composition of the portfolio is fixed, so capital outflows over a long period of time depend on the share of net foreign assets in the long-run portfolio. If this share is negative, TFP growth will then generate capital inflows in the long-run, because it increases the size of the portfolio. If it is positive, it will generate capital outflows. These results do not depend on the particular risk structure of the model. Imperfect substitutability between foreign and domestic assets is enough to generate a well-defined long-run structure of the portfolio, which is at the core of this portfolio growth effect.

This is in stark contrast with the standard neoclassical model without risk. In the absence of risk, domestic and foreign bonds are perfect substitutes, so the initial adjustments in the net foreign asset position that take place to accommodate investment and consumption smoothing persist in the long run, hence the negative correlation of capital outflows with TFP growth. In the presence of risk, these initial adjustments take place as well, but are offset by the rebalancing of the portfolio towards its steady-state structure.

The negative long-run relationship between capital outflows and the capital wedge, and especially the fact that this relationship survives in countries with negative external positions, is a more original fact and is driven by a portfolio composition effect. Here, the fact that risk lies on capital and not on labor income is crucial. In that case, external bonds are not a perfect substitute for domestic capital, but they are for human wealth. If the capital wedge diminishes, the long-run capital stock increases, but human wealth increases less than proportionally because of decreasing marginal returns on capital. This affects the composition of the portfolio by making domestic assets more risky. Holding more foreign assets helps rebalancing the structure of the portfolio towards safe assets, even if the country has a negative external position.

Figures 2 and 3 support our theoretical predictions. They represent the cross-country correlation of capital outflows between 1980 and 2003 in our sample with, respectively, TFP growth and the end-of-period capital per efficient unit of labor, which is a proxy for the capital wedge. ${ }^{3}$ As Panel (a) of Figure 2 shows, the correlation is positive for TFP growth, but it is not robust. Actually, the correlation of capital outflows with TFP growth seems to be driven by a few outliers. If we take a closer look, it appears that, if we exclude the few countries of the sample that have a positive external position at the

\footnotetext{
${ }^{3}$ TFP growth and capital per efficient unit of labor are estimated using a growth-accounting method. This method is described in more details in the paper.
} 
end of the period, the correlation becomes negative. As Figure 3 shows, the correlation between capital per efficient unit of labor and capital outflows is robustly positive on the whole sample (Panel (a)), and stays so even if we exclude countries with a positive external position (Panel (b)). The predictions of our model are consistent with these facts.

As a result, our model predicts accurately the direction of capital flows in the sample. To show this, we perform a calibration analysis where the amount of capital flows predicted by the model are computed and compared to the data. While, consistently with Gourinchas and Jeanne (2009), predicted capital flows are negatively correlated with the actual ones in the riskless approach, the correlation becomes positive in the portfolio approach. Importantly, the capital wedge appears to be crucial in explaining the direction of flows, while TFP catch-up is not. The portfolio approach also reproduces accurately the patterns of capital flows across regions. The fact that global imbalances are mainly driven by Asian countries is explained by their low capital wedge.

Our focus on investment risk is justified by microeconomic studies showing that, on the one hand, risk faced by entrepreneurs is substantial and, on the other, individual risk sharing is limited. For example, Angeletos and Panousi (2009) argue that only $40 \%$ of firms survive after 5 years in the US. Despite this, as stated by Vissin-Jørgensen (2002), "the average household who owns private equity has $82 \%$ of its private equity investment in such a firm". Similarly, Caner and Wolff (2004) show that only 29\% of households have a stock portfolio while $84 \%$ have an access to a saving or checking account. Clearly, investment risk is paramount in less developed economies, where the bulk of production and investment takes place in privately-owned businesses (Gollin, 2008), and where risk-sharing opportunities are even more limited.

Our analysis is performed using Angeletos and Panousi (2009)'s framework, which boils down to a Merton-Samuelson portfolio choice problem between risky capital and safe assets, including human wealth and external bonds. This framework allows to nest both the riskless approach and the approach with risk, which we call the portfolio approach. This model is extended to allow, as in Gourinchas and Jeanne (2009), for TFP growth and a capital wedge accounting for the differences in the long-run capital stock per efficient units of labor.

Some theoretical papers, like Mendoza et al. (2009), Sandri (2010) and Angeletos and Panousi (forthcoming), explain global imbalances by the presence of investment risk, or more generally by the weakness of financial development in emerging countries. ${ }^{4}$ However, the structure of these imbalances and the allocation puzzle have been overlooked. Indeed, to explain global imbalances, most approaches either consider emerging markets as a whole or take Asia (and especially China) in isolation. Aguiar and Amador (2009) are an exception. They explain why countries that grow rapidly tend to accumulate net

\footnotetext{
${ }^{4}$ See, among others, Dooley et al. (2005), Matsuyama (2007), Ju and Wei (2006, 2007), Caballero et al. (2008), Song et al. (2009).
} 
foreign assets rather than liabilities by introducing political economy and contracting frictions. However, their approach is silent on the respective role of the factors of growth.

The remainder of the paper is organized as follows: Section 2 presents the neoclassical growth model with investment risk and its predictions; Section 3 presents the data and the calibration method; Section 4 performs a calibration analysis by comparing actual and predicted flows; Section 5 concludes.

\section{The neoclassical growth model with idiosyncratic in- vestment risk}

In this section, we study the implications in terms of capital flows of the neoclassical growth model with investment risk. To achieve this, we use Angeletos and Panousi (2009)'s model, which generalizes the tractable Merton-Samuelson portfolio choice problem to account for human wealth. This model is extended here to account, as in Gourinchas and Jeanne (2009), for TFP growth and a capital wedge, that is a distortion between the private and social return to capital.

The model is then used to infer the amount of capital flows between an initial period and the steady state and to study the impact of the different factors of growth (TFP catch-up and the capital wedge) on these capital flows.

\subsection{The household's program}

Consider a small open economy with a continuum of length 1 of infinitely-lived households, or families, indexed by $i$. Time is continuous, indexed by $t \in[0, \infty)$. Each household owns a firm which produces a homogeneous good using two factors, labor and capital, according to a Cobb-Douglas technology:

$$
Y_{t}^{i}=F\left(K_{t}^{i}, A_{t} N_{t}^{i}\right)=K_{t}^{i \alpha}\left(A_{t} N_{t}^{i}\right)^{1-\alpha}, 0<\alpha<1
$$

where $K_{t}^{i}$ is the amount of private capital invested in firm $i$ at date $t, N_{t}^{i}$ the amount of labor hired in the firm and $A_{t}$ the deterministic domestic level of technology.

Financial markets are incomplete: households can invest only in their own firm and cannot trade equity. They face an idiosyncratic investment risk, but cannot diversify away this risk through equity or any other means. The only freely traded asset, domestically and internationally, is the riskless bond $B_{t}^{i}$ whose return is fixed internationally to $R^{*}$. Each household is composed of $N_{t}$ members, and each member is endowed with 1 unit of labor which he supplies inelastically in the competitive labor market. Since, 
additionally, there is no aggregate risk, all aggregate variables are deterministic, including the competitive individual wage $w_{t}$. Therefore, labor income is deterministic. The absence of labor income risk and, more generally, of any endowment risk is useful to make the model tractable. But it will also have important consequences on capital flows, since high investment risk relative to labor income risk will make human wealth a closer substitute to safe foreign assets than capital.

Denote household $i$ 's net capital income by $d Q_{t}^{i}$. It is defined as follows:

$$
d Q_{t}^{i}=(1-\tau)\left[F\left(K_{t}^{i}, A_{t} N_{t}^{i}\right)-w_{t} N_{t}^{i}\right] d t-\delta K_{t}^{i} d t+\sigma K_{t}^{i} d v_{t}^{i}
$$

where $w_{t}$ is the wage rate, which is not firm-specific since the labor market is competitive. $\delta$ is the depreciation rate.

Parameter $\tau$ is a wedge on the gross capital return. Following Gourinchas and Jeanne (2006, 2009), it is introduced in order to account for the cross-country differences in capital-labor ratios that are not attributable to TFP. This wedge can be interpreted as a tax on capital income, or as the result of other distortions that would introduce a difference between social and private returns. ${ }^{5}$ We assume that the product of this tax $Z_{t}$ is distributed equally among households:

$$
Z_{t}=\int_{0}^{1} \tau\left[K_{t}^{i \alpha}\left(A_{t} N_{t}^{i}\right)^{1-\alpha}-w_{t} N_{t}^{i}\right] d i
$$

The technology is exactly identical to Gourinchas and Jeanne (2009), except that time is continuous and that firms face investment risk. This risk is introduced here through a standard Wiener process $d v_{t}^{i}$. This process is iid across agents and time and satisfies $E\left[d v_{t}^{i}=0\right]$. This risk can be interpreted as a production or a depreciation shock that affects the return on capital. It is assumed that this shock is averaged out across households, that is: $\int_{0}^{1} d v_{t}^{i}=0$. Parameter $\sigma$ measures the amount of individual risk. Gourinchas and Jeanne (2009)'s specification is nested when $\sigma=0$. $^{6}$

Since the labor market is competitive and the production function has constant returns to scale, then $\tilde{k}_{t}^{i}$, the capital per efficient unit of labor $\tilde{K}_{t}^{i} /\left(A_{t} N_{t}^{i}\right)$, is constant across firms and equal to $\tilde{k}_{t}$. Additionally, capital income is linear in $K_{t}^{i}$, and we can write it as follows:

$$
d Q_{t}^{i}=r_{t} K_{t}^{i} d t+\sigma K_{t}^{i} d v_{t}^{i}
$$

\footnotetext{
${ }^{5}$ In an unreported robustness check (available on request), we consider the hypothesis advanced by Caselli and Feyrer (2007) that the differences in capital stock are due to differences in the relative price of capital and in the share of reproducible capital in production. Our results remain robust in this specification.

${ }^{6}$ In the case with risk, market incompleteness is important: if households were able to diversify perfectly their investment risk, then the model would boil down to the standard neoclassical model without risk. A certain amount of contingent claims could be introduced in order to allow households to decrease their effective level of risk $\sigma$. But what is important for our results is that the final amount of risk remains positive.
} 
where $r_{t}=(1-\tau) f^{\prime}\left(\tilde{k}_{t}\right)-\delta$ is the private net return on capital, with $f(k)=F(k, 1)=k^{\alpha}$.

As in Barro and Sala-i Martin (1995), the household maximizes the following discounted expected welfare of the family members:

$$
U_{t}^{i}=E_{t} \int_{t}^{\infty} N_{s} \ln c_{s}^{i} e^{-\rho(s-t)} d s
$$

where $\rho>0$ is the discount rate and $c_{t}^{i}$ is the individual consumption of the members of household $i$ in period $t$. The population growth rate is supposed to be exogenous and equal to $n$, with $n<\rho$ :

$$
N_{t}=N_{0} e^{n t}
$$

We now turn to the household's budget constraint. The evolution of the household's financial wealth $B_{t}^{i}+K_{t}^{i}$ obeys to:

$$
d\left(B_{t}^{i}+K_{t}^{i}\right)=d Q_{t}^{i}+\left[R^{*} B_{t}^{i}+N_{t} w_{t}+Z_{t}-C_{t}^{i}\right] d t
$$

However, this expression of the budget constraint misses some aspects of household's wealth. Indeed, the household's effective wealth $\Omega_{t}^{i}$ includes his financial wealth, but also human wealth, that is the present discounted value of future labor income and tax product, defined as $H_{t}^{i}=H_{t}=\int_{t}^{\infty} e^{-(s-t) R^{*}}\left(N_{s} w_{s}+Z_{s}\right) d s$. Therefore, $\Omega_{t}^{i}=K_{t}^{i}+B_{t}^{i}+H_{t}$. In order to include human wealth in the budget constraint, we follow Angeletos and Panousi (2009) and use the definition of human wealth to write:

$$
d H_{t}=\left(R^{*} H_{t}-N_{t} w_{t}-Z_{t}\right) d t
$$

It follows from (1), (3) and (4), that the evolution of effective wealth, in per capita terms, can be described by:

$$
d \omega_{t}^{i}=\left[r_{t} k_{t}^{i}+R^{*}\left(b_{t}^{i}+h_{t}\right)-c_{t}^{i}-n \omega_{t}^{i}\right] d t+\sigma k_{t}^{i} d v_{t}^{i}
$$

with $\omega_{t}^{i}=k_{t}^{i}+b_{t}^{i}+h_{t}$. Lower case letters, except $n$, the population's growth rate, stand for per capita (i.e. per family member) values. For each variable $X_{t}^{i}\left(X_{t}\right), x_{t}^{i}\left(x_{t}\right)$ stands for $X_{t}^{i} / N_{t}\left(X_{t} / N_{t}\right)$.

The household maximizes (2) subject to his budget constraint (5), which states that household's wealth is increased by the revenues from capital, whose return $r_{t}+\sigma d v_{t}^{i}$ is risky, and from safe assets, $b_{t}^{i}$ and $h_{t}$, whose return is $R^{*}$, minus consumption. Population growth additionally diminishes the value of wealth per capita. Thanks to the linearity of the budget constraint with respect to wealth, this problem boils down to a tractable Merton-Samuelson portfolio choice problem.

Kraay and Ventura (2000) and Kraay et al. (2005) also applied this portfolio choice approach to the study of capital flows, but in an AK context without human wealth, which is an important variable in this paper. Here, we use a transformation of the budget constraint introduced by Angeletos and Panousi (2009) in order to make human wealth explicitly appear, without impairing the tractability of the problem. 


\subsection{Technology}

The country has an exogenous, deterministic productivity path $\left\{A_{t}\right\}_{t=0, \ldots, \infty}$, which is bounded by the world productivity frontier:

$$
A_{t} \leq A_{t}^{*}=A_{0}^{*} e^{g^{*} t}
$$

The world productivity frontier is assumed to grow at rate $g^{*}$. Following Gourinchas and Jeanne (2009), we define TFP catch-up $\pi_{t}$ as the difference between domestic productivity and the productivity conditional on no technological catch-up:

$$
e^{\pi_{t}}=\frac{A_{t}}{A_{0} e^{g^{*} t}}
$$

We assume that $\pi=\lim _{t \rightarrow \infty} \pi_{t}$ is well defined. Therefore, the growth rate of domestic productivity converges to $g^{*}$. If $\pi>0$, the country has grown faster than the technology frontier and has therefore got closer to it. If $\pi<0$, the country has grown more slowly than the technology frontier and has therefore got farther from it.

\subsection{Household's behavior}

In line with the Merton-Samuelson approach, it follows from the linearity of the budget constraint and the homotheticity of preferences that the capital stock and consumption choices are linear in wealth. ${ }^{7}$ Define $\phi_{t}^{i}=k_{t}^{i} / \omega_{t}^{i}$, the fraction of effective wealth invested in private capital. For a given interest rate $R^{*}$ and a given sequence of wages $\left\{W_{t}\right\}$, the optimal choices of household $i$ are given by:

$$
\begin{gathered}
c_{t}^{i}=(\rho-n) \omega_{t}^{i} \\
r_{t}-R^{*}=\phi_{t} \sigma^{2}
\end{gathered}
$$

Equation (7) shows the familiar result that consumption per capita equals the annualized value of wealth, taking into account population growth. This is a direct consequence of $\log$ utility.

Equation (8) provides a portfolio choice rule. It states that the excess return to capital $r_{t}-R^{*}$ is equal to the risk premium. With logarithmic households, the coefficient of risk aversion is equal to one and the risk premium is the covariance between the return on capital and the return on the portfolio, which is equal here to the variance of the return to capital multiplied by the share of capital in the portfolio.

\footnotetext{
${ }^{7}$ See Kraay and Ventura (2000), Kraay et al. (2005) or Angeletos and Panousi (2009) for a full derivation.
} 


\subsection{Steady state}

The saving rule (7) and the portfolio rule $k_{t}^{i}=\phi_{t} \omega_{t}^{i}$, with $\phi_{t}$ defined by (8), are linear in wealth and can therefore be written in aggregate terms: $c_{t}=(\rho-n) \omega_{t}$ and $k_{t}=\phi_{t} \omega_{t}$, where $\omega_{t}=\int_{0}^{1} \omega_{t}^{i} d i$ is the aggregate value for $\omega_{t}^{i}$. By dividing each side by $A_{t}$, they can also be written in terms of efficient units of labor, denoted $\tilde{c}_{t}, \tilde{k}_{t}$ and $\tilde{\omega}_{t}$.

Capital per efficient units of labor at the firm level, $\tilde{k}_{t}^{i}=K_{t}^{i} / A_{t} N_{t}^{i}$, is constant across firms as a result of competitive labor market. Since the labor market clears $\left(\int N_{t}^{i} d i=N_{t}\right)$, it is equal to its aggregate value $\tilde{k}_{t}=K_{t} / A_{t} N_{t}$.

Equations (7) and (5), when expressed in aggregate terms and divided by $A_{t}$, along with the no-Ponzi conditions and the equilibrium values for $\tilde{w}_{t}, r_{t}$ and $\phi_{t}$, characterize the dynamics of $\tilde{c}_{t}$ and $\tilde{\omega}_{t}$. Once the paths of these variables are known, $\tilde{k}_{t}=\phi_{t} \tilde{\omega}_{t}$, $\tilde{h}_{t}=\int_{0}^{\infty} e^{-\left(R^{*}-\left(n+g^{*}\right)\right) s+\pi_{s}-\pi_{t}}(1-\alpha+\tau \alpha) \tilde{k}_{t+s}^{\alpha} d s$ and $\tilde{b}_{t}=\tilde{\omega}_{t}-\tilde{k}_{t}-\tilde{h}_{t}$ can be determined.

We assume no domestic supply of bonds, so the aggregate demand for bonds $\tilde{b}_{t}$ represents the country's external position.

These equations are used to determine the steady state. We define the steady state by $\dot{\tilde{c}} / \tilde{c}=0$ and $\dot{\pi}_{t}=0$. The following proposition characterizes the steady state. ${ }^{8}$

Proposition 1: If $\sigma>0$, the open economy's steady state exists if and only if $n+g^{*}<R^{*}<\rho+g^{*}$, and the steady-state external bond demand is defined by:

$$
\tilde{b}^{*}(\tau)=\frac{1-\phi^{*}}{\phi^{*}} \tilde{k}^{*}(\tau)-\frac{(1-\alpha+\alpha \tau) f\left(\tilde{k}^{*}(\tau)\right)}{R^{*}-g^{*}-n}
$$

where $\tilde{k}^{*}(\tau)$ and $\phi^{*}$ are defined respectively by:

$$
\begin{gathered}
(1-\tau) f^{\prime}\left(\tilde{k}^{*}\right)-\delta-R^{*}=\sqrt{\sigma^{2}\left(\rho+g^{*}-R^{*}\right)} \\
\phi^{*}=\sqrt{\frac{\rho+g^{*}-R^{*}}{\sigma^{2}}}
\end{gathered}
$$

The condition that the interest rate $R^{*}$ should be strictly lower than the growthadjusted discount rate $\rho+g^{*}$ is a standard condition to insure stationarity in the presence of risk (Aiyagari, 1994). The interest rate should not be too low either: $R^{*}>n+g^{*}$. Otherwise, the long-run human wealth would not be well defined.

The steady-state level of capital is defined through Equation (10) by the equality between the excess return and the steady-state risk premium. Importantly, this links

\footnotetext{
${ }^{8}$ See the Appendix for the proof, originally provided in Angeletos and Panousi (2009). We repeat this material in order to make the paper self-contained, but also to take into account the capital wedge, which is absent in Angeletos and Panousi (2009).
} 
the capital wedge $\tau$ to the long-run capital stock. A lower $\tau$ leads to a higher capital per efficient unit of labor $\tilde{k}^{*}$.

The steady-state share of capital in the portfolio is well-defined and given by Equation (11). In the steady state, the risk premium and therefore the long-run composition of the portfolio between safe and risky assets is defined by the equality between the return of the portfolio and the propensity to consume out of wealth. This is a consequence of risk. Importantly, the share of capital in the portfolio is independent of $\pi$ and $\tau$. This comes from the combination of linear, gaussian returns and homothetic preferences.

Equation (9) gives the excess demand for safe assets, which is equal to domestic demand (first term) minus domestic supply (second term). The sign of demand is ambiguous and depends on $\phi^{*}$, the long-run desired share of risky assets in the portfolio. If $\phi^{*}<1$, which is equivalent to $\sigma^{2}>\rho+g^{*}-R^{*}$, then this demand is positive, and the country has a precautionary demand for safe assets. This condition is satisfied as long as the level of risk in the country is greater than in the rest of the world. ${ }^{9}$ Assuming that the country has a level of risk at least as high as in the rest of the world is consistent with the fact that we are dealing with developing countries. We therefore maintain this assumption in the rest of the paper.

The second term represents the domestic supply for safe assets, which has to be subtracted from the demand for safe asset to obtain external bond holdings. This domestic supply is composed of human wealth, that is, the discounted value of future wages, which constitutes a store of value that can be used as a substitute for bonds. Intuitively, households feel richer if they benefit from steady labor income and therefore need less external bonds to self-insure against investment risk. External bond holdings then result from the demand for safe assets that is not satisfied by human wealth.

\subsection{Capital flows}

Here we explicit capital outflows over a finite period $[0, T]$ as a function of the parameters, especially those at the source of growth and investment, TFP catch-up $\pi$ and the longterm capital per efficient unit of labor $\tilde{k}^{*}$, which is a function of the capital wedge $\tau$.

\footnotetext{
${ }^{9}$ Formally, this argument runs as follows. The constraint that $\phi^{*} /\left(1-\phi^{*}\right)>0$ and equivalently that $\phi^{*}<1$ can be rationalized by the a general equilibrium argument. The world as a whole is in autarky, that is $\tilde{b}_{W}^{*}=0$. According to (9), we have:

$$
\tilde{k}_{W}^{*}=\frac{\phi_{W}^{*}}{1-\phi_{W}^{*}} \frac{\left(1-\alpha+\alpha \tau_{W}\right)\left(\tilde{k}_{W}^{*}\right)^{\alpha}}{R^{*}-g^{*}-n_{W}}
$$

Since $\tilde{k}_{W}^{*}$ is positive, $\phi_{W}^{*} /\left(1-\phi_{W}^{*}\right)$ is necessarily positive and therefore $\phi_{W}^{*}<1$. This is made possible by the adjustment of the world interest rate $R^{*}$ in order to clear the world bond market. If we assume, as in the calibration section, that $\sigma>\sigma_{W}$, then $\phi^{*}<\phi_{W}^{*}$. It is therefore consistent with the portfolio approach to assume that $\phi^{*}<1$.
} 
This is for the purpose of confronting the model with the data, following Gourinchas and Jeanne (2009).

Before deriving the level of bonds predicted by the model, some assumptions must be made. First, we abstract from unobserved future developments in productivity by assuming that all countries have the same productivity growth rate $g^{*}$ after $T$ and that they have reached the steady state at $T$ by making the following assumption:

Assumption 1: $\pi_{t}=\pi$ for all $t \geq T$, and $T$ is sufficiently large to be able to make the following approximation: $\tilde{k}_{t} \simeq \tilde{k}^{*}$ for all $t \geq T .^{10}$

Denote by $\Delta B^{P} / Y_{0}=\left(B_{T}-B_{0}\right) / Y_{0}$ the predicted amount of capital outflows between 0 and $T$ in the portfolio approach. Under Assumption 1, it can be written as follows:

$$
\frac{\Delta B^{P}}{Y_{0}}=e^{\pi+\left(n+g^{*}\right) T} \frac{\tilde{b}^{*}(\tau)}{\tilde{y}_{0}}-\frac{\tilde{b}_{0}}{\tilde{y}_{0}}
$$

where $\tilde{b}^{*}(\tau)$ satisfies Equation (9).

First, we show that, in the portfolio approach, a positive correlation between $\pi$ and capital outflows for countries with positive external positions appears, because capital flows are driven by a portfolio growth effect. Second, we show that, within the portfolio approach, $\tau$ can drive a positive correlation between growth and capital outflows for countries with negative steady-state external positions as well, because capital flows are driven by a portfolio composition effect. This second result is due to the asymmetric effect of capital accumulation on the domestic demand for safe assets and the domestic supply. Finally, we discuss the difference with the riskless approach.

\subsubsection{The role of $\pi$}

Equation (9) is crucial to understand the effect of $\pi$ on capital flows. It states that $\tilde{b}^{*}$ is independent of $\pi$. As a result, for countries that differ only through their TFP catch-up $\pi$, the correlation between growth and capital flows is driven by a portfolio growth effect and depends on the sign of $\tilde{b}^{*}$, which is determined by the other parameters. As a result, TFP growth explains the puzzle only to the extent that countries with positive steady-state external positions drive the observed positive correlation between growth and capital outflows. The effect of $\pi$ on capital outflows in the portfolio approach is

\footnotetext{
${ }^{10}$ The assumption that the country has reached its steady state at $T$ is obviously an unrealistic one, but it is made for the sake of simplicity and for the transparency of the analysis. Indeed, we can restrict the analysis to the steady state and discard issues related to convergence. For robustness checks, we performed the analysis without Assumption 1 and found that relaxing this assumption does not change the results substantially. These results are available on request.
} 
stated more formally in the following Proposition:

Proposition 2: Suppose that Assumption 1 is satisfied. If $\sigma^{2}>0$ and the stationarity conditions of Proposition 1 are satisfied, then capital outflows are increasing in TFP catch-up $\left(\frac{\partial \Delta B}{\partial \pi}>0\right)$ if and only if the long-run external position is positive $\left(\tilde{b}^{*}>0\right)$.

This prediction of the portfolio approach matches the stylized facts represented in Figure 2: TFP catch-up is negatively correlated with capital outflows if the sample is restricted to countries with negative NFA. In the whole sample, the positive correlation is driven by countries with positive external positions.

The intuition can be grasped by considering two countries experiencing the same TFP catch-up, but with different steady-state external positions. In Figure 4, Country 1 has a positive steady-state net foreign asset position. Country 2 has the same level of capital, but has a negative steady-state net foreign asset position. This is the case if, for example, Country 2 has a larger $n$, which makes its level of human wealth higher. We assume for simplicity that TFP catch-up takes place in period 0 and is unexpected. Both countries then converge to a new steady state where the external position, capital and human wealth are all proportional to the initial steady state. This implies a more positive external position in Country 1 and a more negative one in Country 2.

This portfolio growth effect holds for many models that exhibit a well-defined portfolio composition. It is the case of this model due to the presence of risk, which generates a well-defined portfolio allocation between safe and risky assets $\phi^{*}$. This result does not hinge on the particular risk structure that is assumed in the paper, but more generally on the imperfect substitutability between domestic and foreign assets.

\subsubsection{The role of $\tau$}

In this subsection, we show that the stock of capital per efficient unit of labor affects capital flows differently than TFP in the portfolio approach, which could contribute to solve the puzzle. In our model, this variable is isomorphic to the capital wedge $\tau$, for given risk $\sigma$ (see Equation (10)).

Consider Equation (9) again. Contrary to $\pi$, the steady-state excess demand for bonds per efficient unit of labor depends on $\tau$ through the long-run capital stock $\tilde{k}^{*}$. This capital stock has two effects on $\tilde{b}^{*}$ : a positive, linear effect through the precautionary demand for safe assets and a negative, non-linear effect through human wealth. As a result, $\tau$ affects not only the size but also the composition of the portfolio. Its effect on capital outflows will not depend strictly on the sign of $\tilde{b}^{*}$. The following proposition establishes the effect of a local change in $\tau$ on capital flows: 
Proposition 3: Suppose that Assumption 1 is satisfied. If $\sigma^{2}>\rho-R^{*}+g^{*}$ and the stationarity conditions of Proposition 1 are satisfied, then capital outflows are decreasing in the capital wedge $\left(\frac{\partial \Delta B}{\partial \tau}<0\right)$ if and only if $\tilde{b}^{*} \geq-(1-\alpha) \frac{f\left(\tilde{k}^{*}\right)}{R^{*}-n-g^{*}}$.

The proof is provided in the Appendix. The way capital outflows are related to capital per efficient unit of labor (i.e. to the capital wedge) depends on a condition on $\tilde{b}^{*}$ as in the case of TFP-driven growth. However, the condition for capital per efficient unit of labor to generate capital outflows is less restrictive than the condition for TFP catch-up to generate capital outflows. In particular, a positive correlation between capital outflows and investment is compatible now with negative external positions in developing countries. This is consistent with the positive empirical correlation between the long-run capital stock and capital outflows shown in Figure 3, both in the whole sample and in the sample of countries with a negative external position.

The intuition for Proposition 3 is based on Equation (9). A decrease in the capital wedge stimulates capital $\tilde{k}^{*}$ and therefore increases the demand for precautionary assets proportionally. Because capital has a positive effect on production, it also affects positively labor income and human wealth, which constitutes the domestic supply for safe assets. However, the effect on human wealth is less than proportional because the production function - and hence wages, which represent a fraction of production - exhibits decreasing returns to capital. Therefore, the condition for capital outflows to emerge is less restrictive than for TFP growth. In particular, they are not incompatible with a negative external position.

To grasp the intuition further, consider Figure 5. It represents the case where Country 1 and Country 2, starting from the same negative external position, have the same increase in output, but where growth in Country 1 is driven by a higher $\pi$, whereas growth in Country 2 is driven by a lower $\tau$. Because Country 1 starts with a negative external position, it experiences capital inflows, as predicted by Proposition 2. However, Country 2 experiences capital outflows. This can be understood by considering the dynamics of capital and human wealth. In Country 2, growth takes place exclusively through capital accumulation, so the capital stock increases more than in Country 1. On the opposite, human wealth increases less because it exhibits decreasing returns to capital. Country 2 households are therefore exposed to more risk than Country 1 households, but they have access to less safe domestic assets to self-insure against that additional risk. This results in capital outflows in Country 2, since external bonds contribute to self-insure against domestic investment risk.

This portfolio composition effect, contrary to the portfolio growth effect that is at play for $\pi$, hinges more strictly on the specific risk structure of the model. In particular, it is important that foreign assets are a better substitute for human wealth than for private capital, so that growth in private capital generates capital outflows if it is not matched by growth in human wealth, which is the case if growth is originated in a lower 


\subsubsection{Comparison with the riskless approach}

Our results are in stark contrast with those of Gourinchas and Jeanne. They show that, in the riskless approach, the effect of a higher $\pi$ is negative. In the portfolio approach, the effect of $\pi$ is ambiguous. The fundamental difference lies in the fact that in the portfolio approach, the long-run composition of the portfolio is defined by the level of risk and independent of the transitory dynamics. As a result, $\pi$ affects capital outflows through a pure portfolio growth effect. On the contrary, in the riskless approach, the portfolio composition is path-dependent. In particular, any initial adjustment in the external position to meet a desired level of consumption or investment will persist in the long run. Indeed, capital and bonds are both safe assets, so entrepreneurs are perfectly indifferent to their long-run portfolio composition.

In the Appendix, we show that, in the riskless approach, a stationary solution exists for $R^{*}=\rho+g^{*}$ and that capital outflows between 0 and $T$ can be written as follows:

$$
\begin{gathered}
\frac{\Delta B^{R}}{Y_{0}}=-e^{\left(n+g^{*}\right) T}\left(e^{\pi} \tilde{k}^{*}(\tau)-\tilde{k}_{0}\right) \\
-e^{\pi+\left(n+g^{*}\right) T}(1-\alpha+\alpha \tau) f\left(\tilde{k}^{*}(\tau)\right)\left(\int_{0}^{\infty} e^{-\left(R^{*}-g^{*}-n\right) t}\left(1-e^{\pi_{t}-\pi}\right) d t\right)+\tilde{b}_{0}\left(e^{\left(n+g^{*}\right) T}-1\right)
\end{gathered}
$$

We also show that if $\pi_{t}=z(t) \pi$, with $0 \leq z(t) \leq 1, \pi$ has an unambiguously negative effect on capital outflows in our model, as long as $\pi>-100 \%$, which is a mild assumption. Indeed, TFP catch-up pushes the marginal return to capital above the world interest rate, which induces entrepreneurs to invest by borrowing, resulting in a negative effect of TFP on capital outflows (first term). Besides, if households foresee that the domestic TFP will catch up with the world frontier, then they will borrow from the rest of the world in order to smooth consumption (second term). ${ }^{11}$ In the model with risk, similar adjustments in the external position occur during the convergence. However, these initial adjustments are offset in the long run by the desired portfolio composition. ${ }^{12}$

This is illustrated in Figure 6, which simulates the effect of an increase in TFP catch-up at date 0 on the external demand for bond $b_{t}$, starting from the same steady

\footnotetext{
${ }^{11}$ These effects correspond to the "TFP catch-up" and "consumption smoothing" components in Gourinchas and Jeanne.

${ }^{12}$ By comparing Equations (12) and (13), one can think that there is a discontinuity at $\sigma=0$. However, this discontinuity is misleading, because these two equations are derived with different assumptions about the interest rate, for the sake of stationarity. If we assume that $R^{*}<\rho+g^{*}$ and set $\sigma=0$, then consumption and wealth would converge to zero in the long run and we would have $\tilde{\omega}^{*}=0$, which implies $\tilde{b}^{*}(\tau)=-\tilde{k}^{*}(\tau)-\frac{(1-\alpha+\alpha \tau) f\left(\tilde{k}^{*}(\tau)\right)}{R^{*}-g^{*}-n}$. This corresponds to Equation (9), where $\phi^{*} /\left(1-\phi^{*}\right)=-1$, which is precisely the value we obtain when $\sigma$ goes to zero. However, this solution is not stationary.
} 
state, in the riskless and portfolio approaches. In both cases, there is an initial, negative adjustment in the external position. However, in the riskless approach, this initial adjustment persists, whereas it is only temporary in the portfolio approach. The convergence mechanism in the presence of risk is as follows: at impact, the excess return of capital increases, so agents decrease their holdings of bonds in order to invest. This increases the aggregate return of the portfolio, which makes the country more and more wealthy. These returns are invested both in capital and bonds during the transition. As capital increases, the excess return diminishes until it reaches the level that is just sufficient to cover the propensity to consume out of wealth, which defines $\phi^{*}$.

In the riskless approach, the effect of $\tau$ is similar to the effect of $\pi$, in the sense that the long-run effect on capital flows is not governed by a predetermined steady-state portfolio composition, but is path-dependent. To see that, consider Equation (13). $\tau$ affects both the investment and consumption terms (respectively, the first and second terms). These effects represent the initial adjustments in the net foreign asset position that persist in the long run, as in the case of TFP catch-up. A decrease in $\tau$ has a positive effect on the desired capital stock $\tilde{k}^{*}$, which generates capital inflows, because the adjustment in the capital stock takes place through more external indebtedness (first term). Yet, the adjustment in the capital stock does not have a consumption smoothing effect per se, because the capital stock adjusts immediately, so the increase in wages due to the higher capital stock is the same in the long and short run. Indeed, if there is no TFP catch-up (if $\pi_{t}=\pi=0$ ), then the second term in (13) disappears. However, if TFP catch-up is non-zero, a higher capital stock reinforces the consumption smoothing effect of $\pi$, and, depending on $\pi$, the effect can be either positive or negative. As a result, theoretically, if countries have negative TFP catch-up, a negative relationship between capital outflows and growth can be driven by differences in $\tau$ within the riskless approach, if the consumption smoothing effect dominates the investment effect. However, as we will show, this will not be the case in the data.

\section{Calibration}

In the last section, we have shown that the model is able to reproduce the stylized facts highlighted in the introduction. The next step is to check whether this is sufficient for the model to generate the right predictions for capital flows. In order to perform this analysis, we first need either to measure or calibrate the parameters of the model. 


\subsection{Data and calibration method}

We use the same sample of 69 emerging countries as in Gourinchas and Jeanne (2009). ${ }^{13}$ However, Jordan and Angola are removed from this sample because their working-age population does not satisfy $n<\rho$. The sample is therefore reduced to 67 countries.

The parameters which are common across countries also follow their paper: the depreciation rate $\delta$ is set to $6 \%$, the capital share of output $\alpha$ to 0.3 and the growth rate of world productivity $g^{*}$ to $1.7 \%$. Only the discount rate $\rho$ is set to a higher value of $5 \%$ (instead of $4 \%$ ) in order to accommodate high growth rates of labor in the data. ${ }^{14}$ The time span is extended to 1980-2003 (instead of 1980-2000) in order to encompass the recent surge in capital outflows from developing countries and to shed some light on the "global imbalances" debate.

In order to determine the exogenous interest rate, we make the hypothesis that each country is too small to influence the world's demand for bonds. We also assume that the world is composed exclusively of developed countries with zero labor growth and no distortions to the marginal capital return. The world interest rate then corresponds to the autarky steady-state interest rate with $n=0$ and $\tau=0$. In the portfolio approach, the amount of risk $\sigma$ in developed countries is set to 0.3 , which is the amount of entrepreneurial risk commonly reported by empirical studies in the US and the Euro area (Campbell et al., 2001; Kearney and Poti, 2006). This gives $\phi^{*}=13.1 \%$ and $R^{*}=6.55 \%$. If we extend this calibration approach to the case without risk, we get $R^{*}=\rho+g^{*}=6.7 \%$, which is the long-run level of the autarky interest rate when $\sigma=0$.

The amount of risk in emerging countries is set to $\sigma=0.6$, in line with Koren and Tenreyro (2007), who find that the amount of both macroeconomic and idiosyncratic (sectoral) risk is roughly twice as large in developing countries as in industrial ones.

The country-specific data are the paths for output, capital, productivity and workingage population. These data come from Version 6.2 of the Penn World Tables (Heston et al., 2006). Following Gourinchas and Jeanne (2009) and Caselli (2004), the capital stock is constructed with the perpetual inventory method from time series data on real investment. The level of productivity $A_{t}$ is calculated as $\left(y_{t} / k_{t}^{\alpha}\right)^{1 /(1-\alpha)}$ and the level

\footnotetext{
${ }^{13}$ This sample includes: Angola, Argentina, Bangladesh, Benin, Bolivia, Botswana, Brazil, Burkina Faso, Cameroon, Chile, China, Colombia, the Republic of Congo, Costa Rica, Cyprus, Côte d'Ivoire, Dominican Republic, Ecuador, Egypt, Arab Republic, El Salvador, Ethiopia, Fiji, Gabon, Ghana, Guatemala, Haiti, Honduras, Hong Kong, India, Indonesia, Iran, Israel, Jamaica, Jordan, Kenya, Republic of Korea, Madagascar, Malawi, Malaysia, Mali, Mauritius, Mexico, Morocco, Mozambique, Nepal, Niger, Nigeria, Pakistan, Panama, Papua New Guinea, Paraguay, Peru, Philippines, Rwanda, Senegal, Singapore, South Africa, Sri Lanka, Syrian Arab Republic, Taiwan,Tanzania, Thailand, Togo, Trinidad and Tobago, Tunisia, Turkey, Uganda, Uruguay and Venezuela.

${ }^{14}$ Indeed, in the portfolio approach, the world interest rate (i.e. $R^{*}$ ) is lower than $\rho+g^{*}$. If $\rho$ is too small, then we could have $R^{*}-\left(g^{*}+n\right)$ negative or very close to zero. In the first case, capital flows are not well defined; in the second, their variance goes to infinity.
} 
of capital per efficient unit of labor $\tilde{k}_{t}$ as $\left(y_{t} / k_{t}\right)^{1 /(1-\alpha)}$. The level of TFP $A_{t}$ and the capital per efficient unit of labor $\tilde{k}_{t}$ are filtered using the Hodrik-Prescott method in order to suppress business cycles. The parameter $n$ is measured as the annual growth rate of the working-age population. Under Assumption 1, the long-term catch-up $\pi$ can be measured as $\ln \left(A_{T}\right)-\ln \left(A_{0}\right)-T g^{*}$.

The capital wedge $\tau$ is calibrated in order to account exactly for the steady-state stock of capital per efficient unit of labor. We assume that $T=23$ is a sufficiently large number, so $\tilde{k}^{*}$ is approximately equal to $\tilde{k}_{T}$. We thus take $\tilde{k}^{*}=\tilde{k}_{T}$. Then $\tau$ is used to adjust the private marginal return on capital to the world interest rate: $\tau=1-\tilde{k}_{T}^{(1-\alpha)} \frac{R^{*}+\delta+\sqrt{\sigma^{2}\left(\rho+g^{*}-R^{*}\right)}}{\alpha}$. This method assigns a high capital wedge to countries with low end-of-period capital per efficient unit of labor.

Intermediary values of TFP are computed under the assumption that the productivity catch-up follows a linear trend: $\pi_{t}=\pi \min \{t / T, 1\}$. In the portfolio approach, since the stock of capital per efficient unit of labor implied by the model does not jump to its steady state value, its path is approximated by the following formula: $\tilde{k}_{t}=\tilde{k}_{0} e^{\ln \left(\tilde{k}^{*} / \tilde{k}_{0}\right)\left(1-\lambda^{t}\right)}$, where $1-\lambda$ is the convergence rate estimated in our data (that is $1-\lambda=0.3) \cdot{ }^{15}$

Finally, actual capital flows are taken from Lane and Milesi-Ferretti (2006)'s net foreign asset data. They provide estimates for the net external position in current US dollars. ${ }^{16}$ Actual capital outflows during the period, as a share of initial output, are denoted $\frac{\Delta B}{Y_{0}}$.

\subsection{Some key variables}

Table 1 sums up some key parameters given by the calibration method. Consider the long-run productivity catch-up $\pi$ in column (1) of Table 1. On average, non-OECD countries have fallen behind the world frontier in terms of productivity. When looking into details, only Asian countries have caught up with the world productivity. Both Africa and Latin America fell behind.

Column (3) presents the average growth rate of capital $\frac{\Delta \tilde{k}}{T \tilde{y}_{0}}$. The main observation is that the capital stock decreased on average. Consistently with Gourinchas and Jeanne (2006, 2009), emerging countries were not capital-scarce but capital-abundant. Among regions, only Asia increased its capital per efficient unit of labor.

\footnotetext{
${ }^{15}$ The assumed trend is a good proxy for the capital dynamics since the theory predicts that it moves smoothly from $\tilde{k}_{0}$ to $\tilde{k}^{*}$.

${ }^{16}$ These estimates are calculated using the cumulated current account data and are adjusted for valuation effects. In order to be consistent with the PPP-adjusted data used here, a PPP deflator is extracted from the Penn World Table and is used to calculate a PPP-adjusted measure of net external position.
} 
Consider now column (5). When calibrated inside the riskless framework, the average wedge $\tau$ on the net capital return is equal to $38 \%$, which is consistent with the average wedge on gross capital return of $12 \%$ found in Gourinchas and Jeanne (2009). Africa, which has the smallest end-of-period capital level (column (4)), has therefore the highest estimated capital wedge, while Asia's estimated capital wedge is the smallest, since it has the highest end-of-period capital level. The capital wedge calibrated inside the portfolio framework is given by column (6). It is lower than the one reported in column (5) because the risk premium accounts partially for the low levels of capital in developing countries. This leaves unchanged the regions' ranking.

\section{Results}

In this section, we adopt the same approach as Gourinchas and Jeanne (2009): we compute the amount of capital flows predicted by the model and then compare these predicted flows to the actual ones. Gourinchas and Jeanne found that the neoclassical growth model without risk failed in predicting accurately the allocation of capital flows between countries. We show here that the portfolio approach predicts the accurate direction of flows to emerging countries.

\subsection{Riskless approach: the allocation puzzle}

In this subsection, we reproduce the results of Gourinchas and Jeanne on the performances of the neoclassical growth model without risk. We do this for comparison purposes, but also in order to highlight that the dimensions on which the riskless approach fails are consistent with the predictions of the portfolio approach.

Figure 7 summarizes the outcome of the riskless approach across regions. The upper panel reports the actual net capital outflows as a share of initial output $\Delta B / Y_{0}$ : their size is $-46 \%$ on average, which means that emerging countries have received net capital inflows during the period. The middle panel reports the predicted capital outflows based on the model without risk (see Equation (19) in the Appendix). According to the model, non-OECD countries should have received capital inflows on average, which is the case.

However, while satisfying in terms of global trends, the picture is more contrasted when considering the direction and magnitude of flows inside the sample. According to the predictions, Africa and Latin America should have exported capital while Asia should have received capital inflows (middle panel of Figure 7). This is because Asia has benefited from high TFP catch-up during the period while the other regions have fallen behind the world frontier (see Table 1). Asia should have borrowed from the rest of the world both to take advantage of local investment opportunities and to smooth con- 
sumption in the face of rising revenues. Africa and Latin America should have exported capital to seek better returns and to smooth consumption in the face of decreasing revenues relatively to the rest of the world. In the data, the opposite happens (upper panel of the same figure).

However, if we abstract from the sign of capital flows, Latin America and Africa are correctly ranked by the model. Latin America experienced slower TFP growth than Africa and should then have exported more capital, which is consistent with the data. Therefore, Asia appears as an outlier inside the riskless approach.

On the whole, capital seems to flow in the right direction, except for Asia. The same idea emerges from Panel (a) of Figure 8, which shows the scatter plot of actual versus predicted flows. The correlation appears as negative on the whole, which represents the allocation puzzle. However, this negative correlation is driven by a set of countries dominated by Asia, in the upper left of the graph. If we exclude Asian countries and Botswana, the correlation becomes slightly positive. Explaining the allocation puzzle therefore requires to explain the peculiar behavior of Asian countries.

Interestingly, the correlation between predicted and actual flows becomes positive as well if we exclude countries with positive NFA, as shown in Panel (b) of Figure 8. Indeed, many of these countries are Asian countries and were among those driving the negative correlation in Panel (a) (Botswana is in that case too). While the riskless approach becomes consistent when we exclude these countries, it still fails to account for the behavior of the whole sample. Indeed, it predicts that capital outflows should be negatively correlated with TFP catch-up while, in the data, this relationship is unstable, as Figure 2 shows. This instability can, on the contrary, be accounted for by the portfolio approach, since the effect of TFP catch-up depends on the sign of the external position, according to Proposition 2.

\subsection{Portfolio approach}

We have shown that the model without risk reproduces the allocation puzzle, and that this allocation puzzle is mainly driven by Asia, and more generally by countries with a positive external position. We now turn to the extension with risk, and examine whether it solves this anomaly.

\subsubsection{Global imbalances}

We first examine the structure of global imbalances. Contrary to the riskless approach, Asia is not an outlier in the portfolio approach. More importantly, this is not at the expense of another outlier, since Latin America and Africa are still correctly ranked. 
This is because the portfolio approach does not simply reverse the link between growth and capital flows. This link depends in a complex way on the different factors of growth.

The lower panel of Figure 7 reports the estimated predicted net outflows according to Equation (9). Note first that the magnitude of predicted flows is above the actual ones (upper panel) by several orders of magnitude. This is a shortcoming of the portfolio approach that has already been highlighted in Kraay et al. (2005). It can also be related to the home bias in portfolio (Lewis, 1999). But this shortcoming is accentuated here by the presence of potentially huge human wealth, due to labor and productivity growth. In order to obtain more realistic external positions, we can introduce transaction costs, home bias in consumption, sovereign risk, or any other feature that generates a home bias in asset holdings. ${ }^{17}$ Additionally, one can introduce limited pledgeability. Indeed, our model suggests that the totality of human wealth can be pledged to creditors, which is not realistic. This would dampen the effect of human wealth on the magnitude. Our predictions would nevertheless survive as the effects of TFP growth and the capital wedge do not depend on the magnitude of the portfolio but on its structure.

When abstracting from the magnitude issue, it appears that the predicted outflows in the lower panel of Figure 7 exhibit the right sign, which is negative, and, contrary to the riskless approach, the right ranking between regions. According to the model's predictions, Africa and Latin America should receive capital inflows while Asia should export capital, as in the data. Additionally, the model predicts accurately that Africa should receive more capital inflows than Latin America.

This analysis sheds some light on a neglected issue in the studies on global imbalances. Namely: why are these imbalances originated in Asia and not in other developing regions? An answer suggested here is that Asian growth is originated not only in TFP growth, but also, importantly, in a larger long-run capital per efficient unit of labor (equivalently, lower distortions $\tau$ ). As a consequence, growth had benefited both to capital and labor income, but this growth has been slightly tilted towards capital. Therefore, the asset demand due to a large capital accumulation has not been compensated by a matching increase in human wealth -although human wealth has grown a lot. This resulted in capital outflows. On the opposite, Africa and Latin America face large frictions on the return to capital, which implies that their human wealth is large relative to their capital stock. Their asset demand is then low relative to their asset supply, leading to capital inflows.

Not only does the portfolio approach rationalize the behavior of Asia relative to other regions, but it also explains the difference between Africa and Latin America. Both regions have low capital per efficient unit of labor, but this is especially true for Africa, which has a higher level of distortions. Human wealth is then particularly disproportionate as compared to capital in Africa. This results in larger capital inflows

\footnotetext{
${ }^{17}$ In Kraay et al. (2005), the magnitude of capital flows becomes more realistic when they introduce sovereign risk.
} 
in Africa than in Latin America.

\subsubsection{Solving the allocation puzzle}

We now turn to the cross-country predictions of capital flows. The portfolio approach seems to be a better predictor, if not of the magnitude of flows, at least of their direction. Panel (a) of Figure 9 sums up this idea by plotting predicted flows according to the portfolio approach against the actual ones. A positive correlation appears. Besides, this correlation is not driven by Asian countries or other outliers as Botswana, contrary to the riskless approach. Moreover, the slope of the fitted values barely changes when we exclude Asian countries and Botswana, meaning that these economies fit into the model just as well as the others. The positive correlation is not driven either by countries with positive NFA, as Panel (b) shows.

Figure 10 gives a sense of the contribution of the different factors to the positive correlation between actual and predicted flows within the portfolio approach. We set successively $\tau$ and $\pi$ to zero, since they are the main focus of the paper. We check whether one of these variables is essential to generate the results. According to Panel (a), the fit of the model is unaffected if we set $\pi=0$. In particular, the t-statistic remains at the same level as in the baseline. In the case where $\pi=0$, all countries grow at the same rate as the world frontier, $g^{*}$, but they still have the same external position in terms of efficient units of labor $\tilde{b}^{*}(\tau)$ as in the baseline. This means that the variations in $\tilde{b}^{*}(\tau)$ participates substantially in explaining the direction of flows.

Finally, we examine the contribution of $\tau$. In Panel (b), we set $\tau=0$, which amounts to imposing a common level of long-run capital stock per efficient unit of labor $\tilde{k}^{*}$. Predicted capital outflows are then driven by variations in human wealth due to $n$ or by variations in $\pi$. The slope of the fitted values is now diminished and the t-statistic is now equal to 1.24, which means that the slope is not significant. Differences in $\tau$ (equivalently, differences in the long-term capital stock $\tilde{k}^{*}$ ) is therefore a key factor to explain capital flows.

\subsubsection{Alternative values of risk}

Idiosyncratic risk is a very difficult parameter to assess, in particular in developing countries. The value that we assigned to $\sigma$ in the calibration, 0.6 , is then questionable. In Graph (a) of Figure 11, the scatter plots of observed versus predicted flows for different values of $\sigma$ are represented. According to the graph, the higher $\sigma$, the larger the predicted capital outflows for each country. Indeed, $\sigma$ affects negatively $\phi^{*}$, the share of capital in the portfolio: $\sigma$ increases the need for precautionary savings for a given level of capital. As a result, the plots are shifted to the left or to the right relative to the baseline but 
the correlation is still positive.

The value of $\sigma$ in developed countries, 0.3, must be challenged as well. This is achieved by making the world interest rate $R^{*}$ vary. Indeed, the channel through which a higher risk in developed countries manifests itself is a lower world interest rate. Graph (b) of Figure 11 provides the scatter plots with different levels of interest rate. It appears that lower risk in the rest of the world (i.e. higher interest rate) has the same effect as higher risk in developing countries: it increases predicted outflows but does not alter the correlation.

\section{Conclusion}

This paper develops an extension of the traditional neoclassical growth model to risky investment that contributes to match the actual capital flows and to solve the allocation puzzle. It also provides an explanation to global imbalances and to their regional structure. Namely, it explains why capital flows to the North come from Asia and not from other regions with poor financial development as Africa and Latin America. The advantage of this approach is that it does not constitute a great departure from the textbook model and therefore allows the adoption of a development accounting approach.

One further step in this line of research would consist in studying whether the portfolio approach can also account for the composition of flows. Extending the model to the possibility to trade equity, at least partially, could help predict both equity and bond holdings. One could then check whether the portfolio approach is consistent with the fact that direct foreign investment is positively correlated with growth, while securities are not, as shown by Prasad et al. (2007).

\section{References}

Aguiar, M. and M. Amador (2009), 'Growth in the shadow of expropriation', Mimeo.

Aiyagari, S. R. (1994), 'Uninsured idiosyncratic risk and aggregate saving, $\check{T}$ ', Quarterly Journal of Economics 109, 659-84.

Aizenman, J. and A. Pinto, B.and Radziwill (2007), 'Sources for financing domestic capital: Is foreign saving a viable option for developing countries?', Journal of International Money and Finance 26(5), 682-702.

Angeletos, G.-M. and V. Panousi (2009), 'Revisiting the supply side effects of government spending', Journal of Monetary Economics 56(2), 137-153. 
Angeletos, G.-M. and V. Panousi (forthcoming), 'Financial integration, entrepreneurial risk and global imbalances', Journal of Economic Theory.

Barro, R. J. and X. Sala-i Martin (1995), Economic Growth, McGraw Hill, New York.

Bernanke, B. and R. Gurkaynak (2001), N.B.E.R. Macroeconomics Annual, MIT Press Cambridge MA, chapter Is Growth Exogenous? Taking Mankiw, Romer and Weil seriously, pp. 11-72.

Caballero, R. J., E. Farhi and P.-O. Gourinchas (2008), 'An equilibrium model of "global imbalances" and low interest rates', American Economic Review 98(1), 358-93.

Campbell, J.Y., M. Lettau, B.J. Malkiel and Y. Xu (2001), 'Have individual stocks become more volatile? an empirical exploration of idiosyncratic risk', Journal of Finance 56(1), 1-43.

Caner, A. and E. N. Wolff (2004), 'Asset poverty in the united states, 1984-99: Evidence from the panel study of income dynamics', Review of Income and Wealth 50(4), 493518.

Caselli, F. (2004), 'Accounting for cross-country income differences', NBER Working Paper No 10828.

Caselli, F. and J. Feyrer (2007), 'The marginal product of capital', Quarterly Journal of Economics 122, 535-68.

Dooley, M. P., D. Folkerts-Landau and P. Garber (2005), 'The us current account deficit and economic development: Collateral for a total return swap', Proceedings, Federal Reserve Bank of San Francisco, Issue Feb.

Gollin, D. (2008), 'Nobody's business but my own: Self-employment and small enterprise in economic development', Journal of Monetary Economics 55(2), 219-233.

Gourinchas, P-O. and O. Jeanne (2006), 'The elusive gains from international financial integration', Review of Economic Studies 73, 715-41.

Gourinchas, P.-O. and O. Jeanne (2009), 'Capital flows to developing countries: The allocation puzzle', Peterson Institute Working Paper Series WP09-12.

Hall, R. E. and C. I. Jones (1999), 'Why do some countries produce so much more output than others?', The Quarterly Journal of Economics 114(1), 83-116.

Heston, A., R. Summers and B. Aten (2006), 'Penn world table version 6.2', Center for International Comparisons of Production, Income and Prices at the University of Pennsylvania.

Hsieh, C.-T. and P.J. Klenow (2007), 'Relative prices and relative prosperity', American Ecnomic Review 97(3), 562-85. 
Ju, J. and S.-J. Wei (2006), 'A solution to two paradoxes of international capital flows', NBER Working Paper No 12668.

Ju, J. and S.-J. Wei (2007), 'Domestic institutions and the bypass effect of financial globalization', NBER Working Paper No 13148.

Kearney, C. and V. Poti (2006), 'Have european stocks become more volatile? an empirical investigation of idiosyncratic and market risk in the euro area', The Institute for International Integration Studies Discussion Paper Series iiisdp132, IIIS.

Koren, M. and S. Tenreyro (2007), 'Volatility and development', Quarterly Journal of Economics 122(1), 243-87.

Kraay, AArt and Jaume Ventura (2000), 'Current accounts in debtor and creditor countries', The Quarterly Journal of Economics 115(4), 1137-1166.

Kraay, AArt, Norman Loayza, Luis Serven and Jaume Ventura (2005), 'Country portfolios', Journal of the European Economic Association 3(4), 914-945.

Lane, Philip R. and Gian Maria Milesi-Ferretti (2006), 'The external wealth of nations mark ii: Revised and extended estimates of foreign assets and liabilities for industrial and developing countries, 1970-2004', IMF Working Paper (69).

Lewis, K. (1999), 'Trying to explain home bias in equities and consumption', Journal of Economic Literature 37(2), 571-608.

Matsuyama, K. (2007), 'Credit traps and credit cycles', American Economic Review 97(1), 503-516.

Mendoza, E. G., V. Quadrini and J.-V. Ríos-Rull (2009), 'Financial integration, financial development, and global imbalances', Journal of Political Economy 117(3), 371-416.

Prasad, E., R. Rajan and A. Subramanian (2007), 'Foreign capital and economic growth', Brookings Papers on Economic Activity 1(2007-1), 153-230.

Sandri, D. (2010), 'Growth and capital flows with risky entrepreneurship', IMF Working Paper WP/10/37.

Song, Z.M., K. Storesletten and F. Zilibotti (2009), 'Growing like china', CEPR Working Paper No DP7149.

Vissin-Jørgensen, A. (2002), 'Limited asset market participation and the elasticity of intertemporal substitution', Journal of Political Economy 110, 825-53. 


\section{Appendix}

\section{Proof of Proposition 1}

In order to prove Proposition 1, we first establish the following Lemma:

Lemma 1: Let $\tilde{x}_{t}=X_{t} /\left(A_{t} N_{t}\right)$ denote the value of $X_{t}$ in efficient labor terms at the aggregate level. For a given interest rate $R^{*}$, the aggregate dynamics of the economy is characterized by:

$$
\begin{gathered}
\tilde{c}_{t}=(\rho-n) \tilde{\omega}_{t} \\
\frac{\dot{\tilde{\omega}}_{t}}{\tilde{\omega}_{t}}=r_{t} \phi_{t}+R^{*}\left(1-\phi_{t}\right)-\left(\rho+g^{*}+\dot{\pi}_{t}\right)
\end{gathered}
$$

where $r_{t}=r\left(\phi_{t} \tilde{\omega}_{t}\right)=(1-\tau) \alpha\left(\phi_{t} \tilde{\omega}_{t}\right)^{\alpha-1}-\delta$ and $\phi_{t}$ defined by equation (8).

Equation (14) is the counterpart of Equation (7) in terms of efficient units of labor.

Equation (15) is obtained from the aggregation of the individual budget constraints (5) written in terms of efficient units of labor and where the wage clears the labor market.

Equations (14) and (15), along with the no-Ponzi conditions and the definitions of $r_{t}$ and $\phi_{t}$, characterize the dynamics of $\tilde{c}_{t}$ and $\tilde{\omega}_{t}$. Once the paths of these variables are known, $\tilde{k}_{t}=\phi_{t} \tilde{\omega}_{t}, \tilde{h}_{t}=\int_{0}^{\infty} e^{-\left(R^{*}-\left(n+g^{*}\right)\right) s+\pi_{s}-\pi_{t}}(1-\alpha+\tau \alpha) \tilde{k}_{t+s}^{\alpha} d s$ and $\tilde{b}_{t}=\tilde{\omega}_{t}-\tilde{k}_{t}-\tilde{h}_{t}$ can be determined. However, these equations are used here only to determine steady state.

We now characterize stationarity.

Since, according to Equation (14), consumption is proportional to wealth, the stationarity of consumption $\dot{\tilde{c}} / \tilde{c}=0$ implies the stationarity of wealth $\dot{\tilde{\omega}} / \tilde{\omega}=0$. Additionally, the stationarity of catch-up $\dot{\tilde{\pi}}=0$, along with the aggregate budget constraint, implies that the long-run share of capital $\phi^{*}$ satisfies:

$$
r^{*} \phi^{*}+R^{*}\left(1-\phi^{*}\right)-\left(\rho+g^{*}\right)=0
$$

which is equivalent to:

$$
\frac{\left(r^{*}-R^{*}\right)^{2}}{\sigma^{2}}=\rho+g^{*}-R^{*}
$$

Therefore, for the steady state to exist, we must have $R^{*} \leq \rho+n$.

To establish that $R^{*}<\rho+n$, notice that Equation (16) can be rewritten as follows:

$$
\sigma^{2} \phi^{* 2}=\rho+g^{*}-R^{*}
$$


Suppose that $R^{*}=\rho+g^{*}$. Since $\sigma>0$, this would imply that $\phi^{*}=0$. If wealth is stationary, this means that the stock of capital converges to zero. Given the CobbDouglas specification, this implies that the return to capital would tend to infinity, which contradicts the fact that the return differential is finite, as suggested by Equation (16). Since, as shown above, $R^{*} \leq \rho+g^{*}$, then we must have $R^{*}<\rho+g^{*}$.

Since the share of capital in wealth $\phi$ is necessarily non-negative, then $r-R^{*}$ is also non-negative. Equation (16) therefore yields the expression of the return differential:

$$
r^{*}-R^{*}=\sqrt{\sigma^{2}\left(\rho+g^{*}-R^{*}\right)}
$$

Since $(1-\tau) f^{\prime}\left(k^{*}\right)-\delta=r^{*}$, this equation is equivalent to Equation (10). It also characterizes $k^{*}$.

Similarly, using the fact that $\phi^{*}=\left(r-R^{*}\right) / \sigma^{2}$, we can show that Equation (16) implies that:

$$
\phi^{*}=\sqrt{\frac{\rho+g^{*}-R^{*}}{\sigma^{2}}}
$$

which corresponds to Equation (11).

Equation (9) derives from the definition of $\phi$ at steady state:

$$
\phi^{*}=\tilde{k}^{*} /\left(\tilde{k}^{*}+\tilde{b}^{*}+\tilde{h}^{*}\right)
$$

where $k^{*}$ is characterized by (10) and $\phi^{*}$ by (11)

Finally, to complete Equation (9), we have to determine $\tilde{h}$ at steady state. $\tilde{h}_{t}=$ $\int_{0}^{\infty} e^{-R^{*} s} \frac{N_{t+s} A_{t} t+s}{N_{t} A_{t} t}(1-\alpha+\tau \alpha) \tilde{k}_{t+s}^{\alpha} d s=\int_{0}^{\infty} e^{-\left(R^{*}-\left(n+g^{*}\right)\right) s+\pi_{s}-\pi_{t}}(1-\alpha+\tau \alpha) \tilde{k}_{t+s}^{\alpha} d s$. Equation (10) gives $\tilde{k}^{*}$, the steady-state value of $\tilde{k}$. We have also $\pi_{t}=\pi$ in the long run. Therefore,

$$
\tilde{h}^{*}=\frac{(1-\alpha+\tau \alpha) f\left(\tilde{k}^{*}\right)}{R^{*}-\left(n+g^{*}\right)}
$$

Replacing $\tilde{h}^{*}$ in Equation (17) yields Equation (9).

\section{Proof of Proposition 3}

Notice that the predicted capital flows must satisfy (12). According to this equation the derivative of $\frac{\Delta B}{Y_{0}}$ with respect to $\tau$ depends only on the derivative of $\tilde{b}^{*}$.

Differentiating (9) with respect to $\tau$, we obtain:

$$
\frac{\partial \tilde{b}^{*}}{\partial \tau}=\frac{\partial \tilde{k}^{*}}{\partial \tau}\left[\frac{1-\phi^{*}}{\phi^{*}}-\frac{(1-\alpha+\tau \alpha) \alpha \tilde{k}^{*(\alpha-1)}}{R^{*}-n-g^{*}}\right]-\frac{\alpha \tilde{k}^{* \alpha}}{R^{*}-n-g^{*}}
$$


In order to infer $\frac{\partial \tilde{k}^{*}}{\partial \tau}$, we differentiate Equation (10) with respect to $\tau$ and get:

$$
\frac{\partial \tilde{k}^{*}}{\partial \tau}=\frac{\tilde{k}^{*}}{(1-\tau)(1-\alpha)}
$$

Replacing in $\frac{\partial \tilde{b}^{*}}{\partial \tau}$, we can show that:

$$
\frac{\partial \tilde{b}^{*}}{\partial \tau}=\frac{1}{(1-\tau)(1-\alpha)}\left[-\tilde{b}^{*}-(1-\alpha) \frac{\tilde{k}^{* \alpha}}{R^{*}-n-g^{*}}\right]
$$

Therefore, $\frac{\partial \tilde{b}^{*}}{\partial \tau} \leq 0$ if and only if $\tilde{b}^{*} \geq-(1-\alpha) \frac{\tilde{k}^{* \alpha}}{R^{*}-n-g^{*}}$.

\section{Derivation of Equation (13)}

When $\sigma=0$, the no-arbitrage condition $r_{t}=R^{*}$ is necessarily satisfied for all $t$. Otherwise, according to the expression of $\phi_{t}(8)$, the stock of capital would be infinite. Therefore, the stationarity of wealth implies:

$$
R^{*}=\rho+g^{*}
$$

Using (14) and (15) in per capita terms, along with the fact that $r_{t}=R^{*}$ and $R^{*}=\rho+g^{*}$, we obtain the following Euler condition:

$$
\frac{\dot{c}_{t}}{c_{t}}=g^{*}
$$

Therefore, $c_{t}=c_{0} e^{g^{*} t}$, and $\tilde{c}_{t}=\tilde{c}_{0} e^{g^{*} t} A_{0} / A_{t}=\tilde{c}_{0} e^{-\pi_{t}}$. As a consequence, we obtain at steady state: $\tilde{c}^{*}=\tilde{c}_{0} e^{-\pi}$. We know also that $\tilde{k}_{t}=\tilde{k}^{*}$ always because of the no-arbitrage condition. The stationarity of wealth therefore implies that $\tilde{b}^{*}$ is also constant in the long run and satisfies:

$$
\tilde{\omega}^{*}=\tilde{k}^{*}+\tilde{b}^{*}+\tilde{h}^{*}
$$

Since $\tilde{c}^{*}=(\rho-n) \tilde{\omega}^{*}=\left(R^{*}-\left(n+g^{*}\right)\right) \tilde{\omega}^{*}$ and, as we have shown above, $\tilde{h}^{*}=$ $(1-\alpha+\tau \alpha) \tilde{k}^{* \alpha} /\left(R^{*}-\left(n+g^{*}\right)\right)$, this equation can be rewritten as follows:

$$
\tilde{b}^{*}=-\tilde{k}^{*}-\frac{(1-\alpha+\tau \alpha) \tilde{k}^{* \alpha}}{R^{*}-\left(n+g^{*}\right)}+\frac{\tilde{c}_{0} e^{-\pi}}{R^{*}-\left(n+g^{*}\right)}
$$

Replacing $\tilde{c}_{0}$ using $\tilde{c}_{0}=(\rho-n) \tilde{\omega}_{0}$, we obtain:

$$
\tilde{b}^{*}=-\tilde{k}^{*}-\frac{(1-\alpha+\tau \alpha) \tilde{k}^{* \alpha}}{R^{*}-\left(n+g^{*}\right)}+e^{-\pi}\left[\tilde{h}_{0}+\tilde{k}_{0}+\tilde{b}_{0}\right]
$$


Replacing this expression for $\tilde{b}^{*}$ in Equation (12) and substituting for $\tilde{h}_{0}=(1-\alpha+$ $\alpha \tau) f\left(\tilde{k}^{*}\right) \int_{0}^{\infty} e^{-\left(R^{*}-\left(n+g^{*}\right)\right) t+\pi_{t}} d t$, we obtain:

$$
\begin{gathered}
\frac{\Delta B^{R}}{Y_{0}}=-e^{\left(n+g^{*}\right) T} \frac{e^{\pi} \tilde{k}^{*}(\tau)-\tilde{k}_{0}}{f\left(\tilde{k}_{0}\right)} \\
-e^{\pi+\left(n+g^{*}\right) T} \frac{(1-\alpha+\alpha \tau) f\left(\tilde{k}^{*}\right)}{f\left(\tilde{k}_{0}\right)}\left(\frac{1}{R^{*}-\left(n+g^{*}\right)}-\int_{0}^{\infty} e^{-\left(R^{*}-\left(n+g^{*}\right)\right) t+\pi_{t}-\pi} d t\right)+\frac{\tilde{b}_{0}}{f\left(\tilde{k}_{0}\right)}\left(e^{\left(n+g^{*}\right) T}-1\right)
\end{gathered}
$$

Since $1 /\left(R^{*}-\left(n+g^{*}\right)\right)=\int_{0}^{\infty} e^{-\left(R^{*}-\left(n+g^{*}\right)\right) t} d t$, this expression leads to Equation (13).

\section{Productivity and consumption smoothing}

When $\sigma=0$, if $\pi_{t}=z(t) \pi$, with $0 \leq z(t) \leq 1$, the second term of Equation (13) can be written as follows:

$$
\frac{\Delta B^{s}}{Y_{0}}=-e^{\left(n+g^{*}\right) T} \frac{(1-\alpha+\alpha \tau) f\left(\tilde{k}^{*}\right)}{f\left(\tilde{k}_{0}\right)} \int_{0}^{T} e^{-(\rho-n) t}\left(e^{\pi}-e^{\pi z(t)}\right) d t
$$

A sufficient condition for $\frac{\Delta B^{s}}{Y_{0}}$ to be decreasing in $\pi$ is that $e^{\pi}-e^{\pi z(t)}$ is increasing in $\pi$. We have:

$$
\frac{\partial\left[e^{\pi}-e^{\pi z(t)}\right]}{\partial \pi}=e^{\pi}-z(t) e^{\pi z(t)}
$$

$$
\text { If } \pi \geq 0 \text {, then } \partial\left[e^{\pi}-e^{\pi z(t)}\right] / \partial \pi \geq 0 \text { for } z(t) \in[0,1] \text {. }
$$

Now consider the case $\pi<0$. Notice that $\partial\left[e^{\pi}-e^{\pi z(t)}\right] / \partial \pi=0$ for $z(t)=1$. Therefore, if $\partial\left[e^{\pi}-e^{\pi z(t)}\right] / \partial \pi$ is decreasing in $z(t)$ for $z(t) \in[0,1]$, then $\partial\left[e^{\pi}-e^{\pi z(t)}\right] / \partial \pi \geq$ 0 for $z(t) \in[0,1]$. Consider the derivative of $\partial\left[e^{\pi}-e^{\pi z(t)}\right] / \partial \pi$ with respect to $z(t)$ :

$$
\frac{\partial\left[e^{\pi}-e^{\pi z(t)}\right]}{\partial z(t)}=-(\pi z(t)+1) e^{\pi z(t)}
$$

This term is negative for all $z(t) \in[0,1]$ if $\pi>-1$. Therefore, $\partial\left[e^{\pi}-e^{\pi z(t)}\right] / \partial \pi \geq 0$ for $z(t) \in[0,1]$ for $\pi<-1$ as well.

As a result, $\frac{\Delta B^{s}}{Y_{0}}$ is decreasing in $\pi$ for $\pi<-1$. 


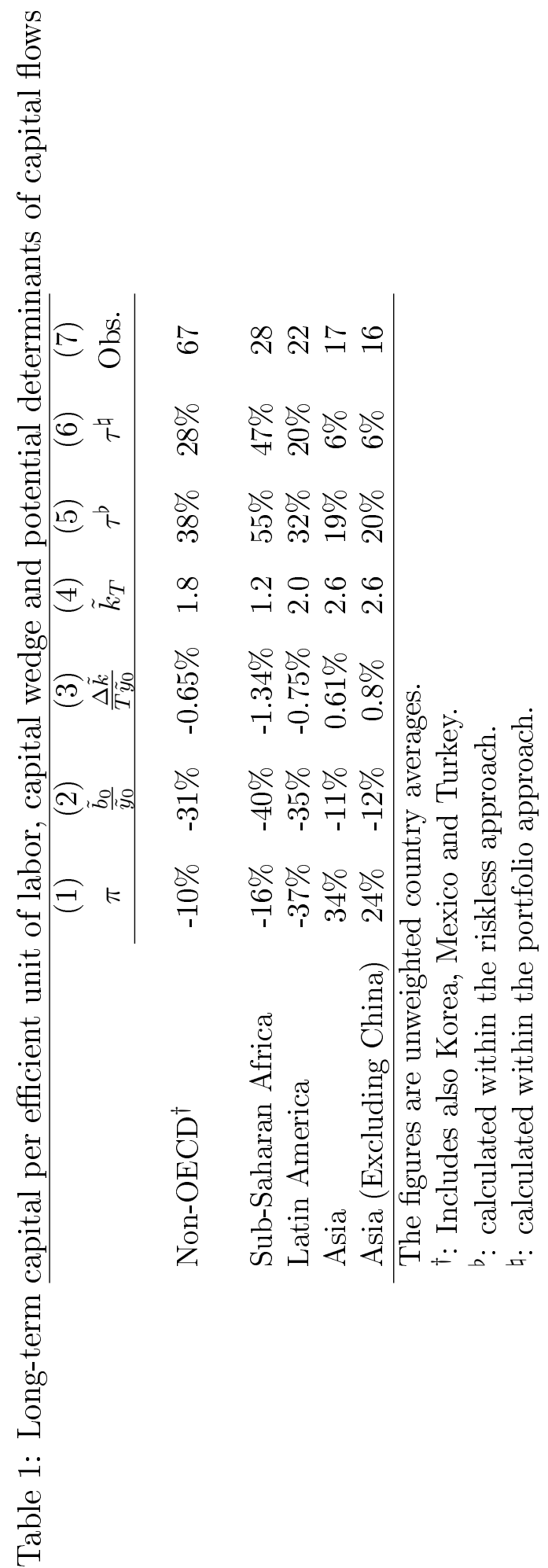


Figure 1: Capital outflows against growth of output per worker - 1980-2003

(a)

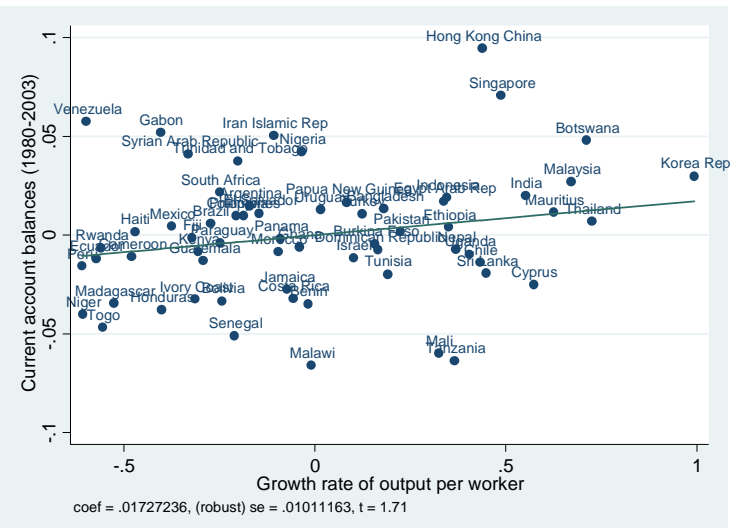

(b)

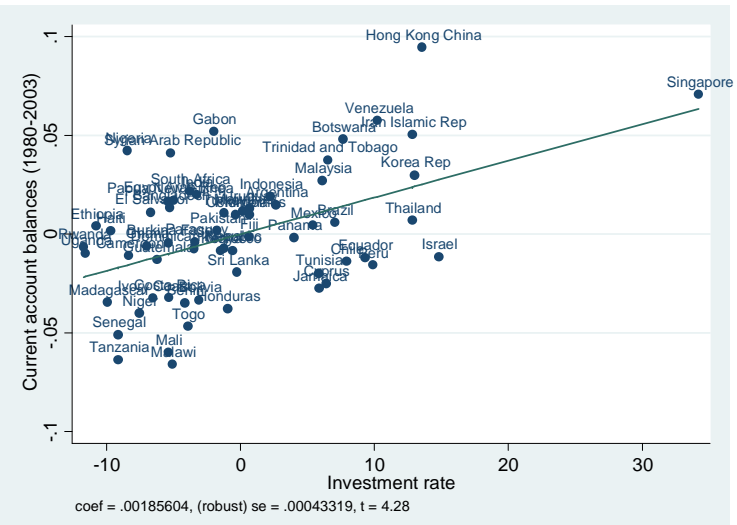

Source: Penn World Tables 6.2 (Heston et al., 2006), Lane and Milesi-Ferretti (2006), author's calculations.

Panel (a): the variables used are residuals from a regression on growth of output per worker. Panel (b): The variables used are residuals from a regression on investment rates.

Figure 2: Capital outflows against TFP catch-up - 1980-2003

(a) Whole sample

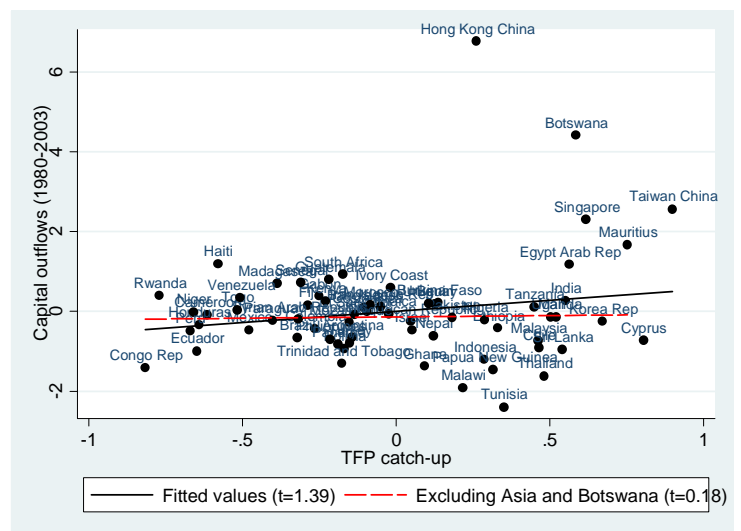

(b) Excluding positive NFA

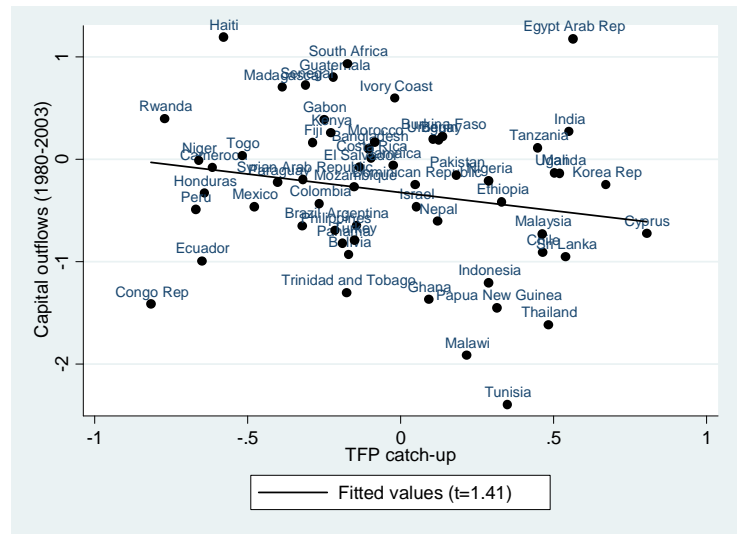

Source: Penn World Tables 6.2 (Heston et al., 2006), Lane and Milesi-Ferretti (2006), author's calculations.

Note China is excluded from the figure.

TFP growth is estimated as $\pi=\ln \left(A_{T}\right)-\ln \left(A_{0}\right)$, where $A_{t}$ is the trend of TFP, measured through a growth accounting method. See Section 3 for details.

The variables used are residuals from a regression on long-term capital stock per efficient unit of labor. 
Figure 3: Capital outflows against the long-term capital stock per efficient unit of labor - 1980-2003

(a) Whole sample

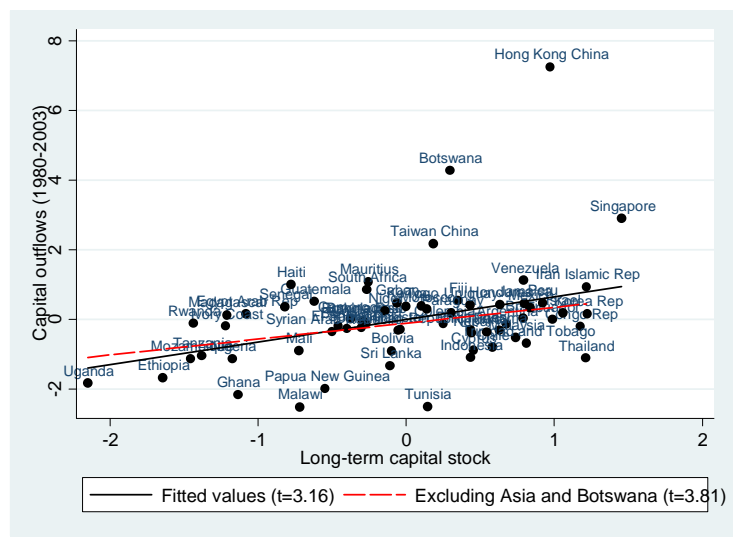

(b) Excluding positive NFA

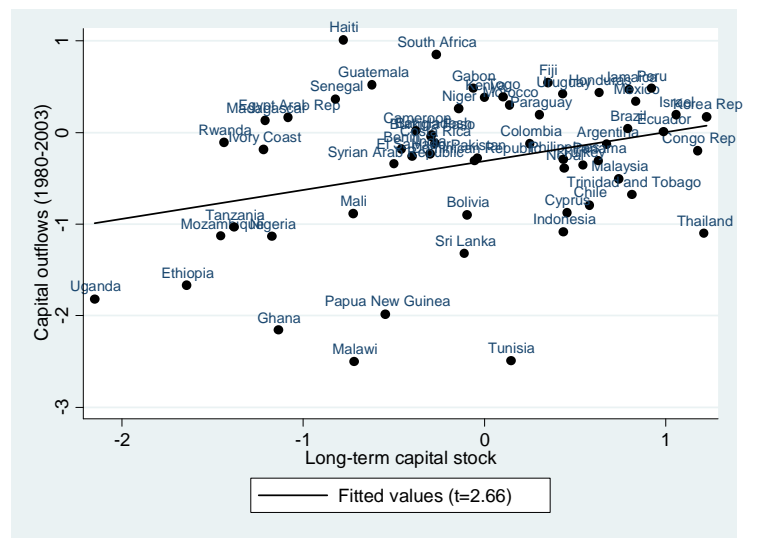

Source: Penn World Tables 6.2 (Heston et al., 2006), Lane and Milesi-Ferretti (2006), author's calculations.

Note: China is excluded from the figure.

The long-term capital stock per efficient unit of labor is the TFP-adjusted capital/labor ratio at the end of the sample. It is measured as $\tilde{k}_{t}=K_{t} /\left(A_{t} N_{t}\right)$, where $K_{t}$ is the aggregate capital stock, $A_{t}$ is TFP and $L_{t}$ is the labor force, and then cleaned from short-run fluctuations. See Section 3 for details. The variables used are residuals from a regression on TFP catch-up. 
Figure 4: Effect of TFP on capital outflows - Positive versus negative long-run external position
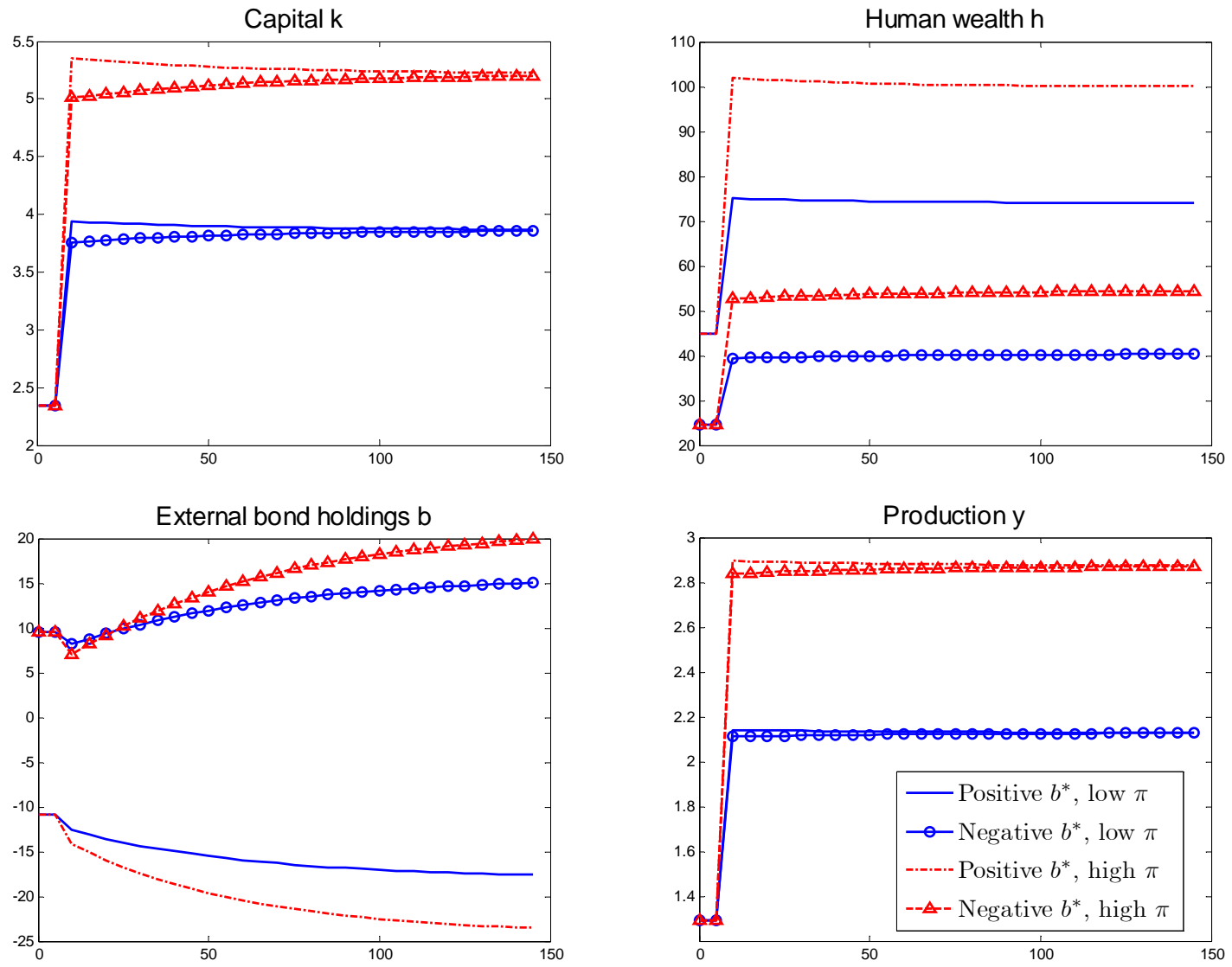
Figure 5: Effect of higher $\pi$ versus lower $\tau$

Capital k

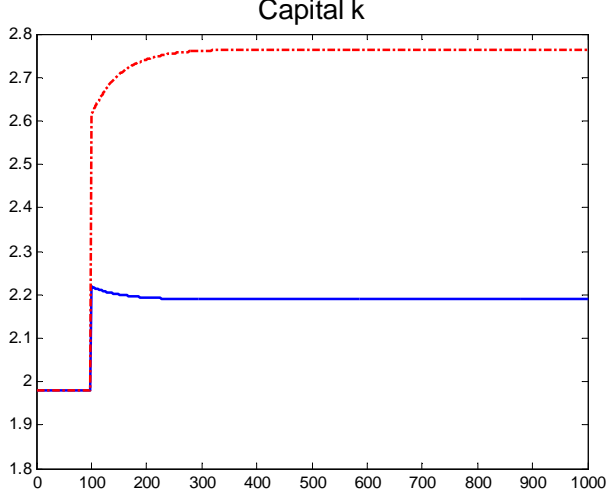

External bond holdings $b$

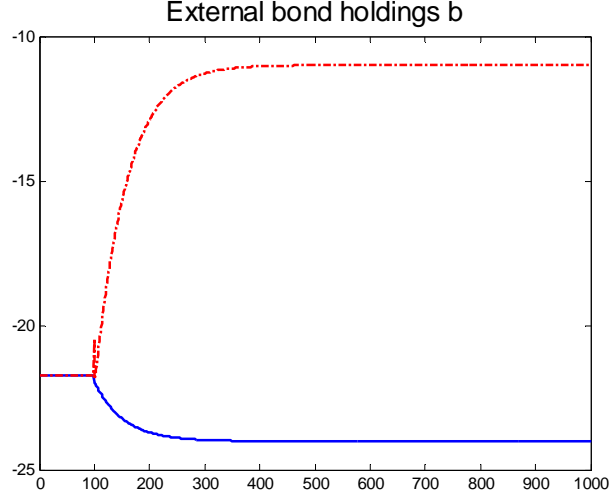

Human wealth $\mathrm{h}$

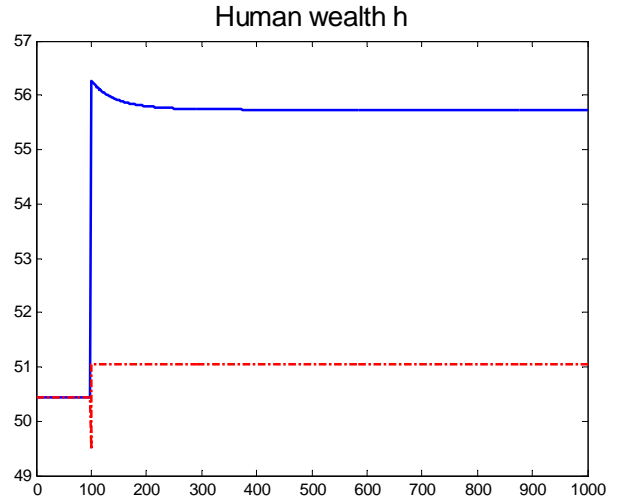

Production y

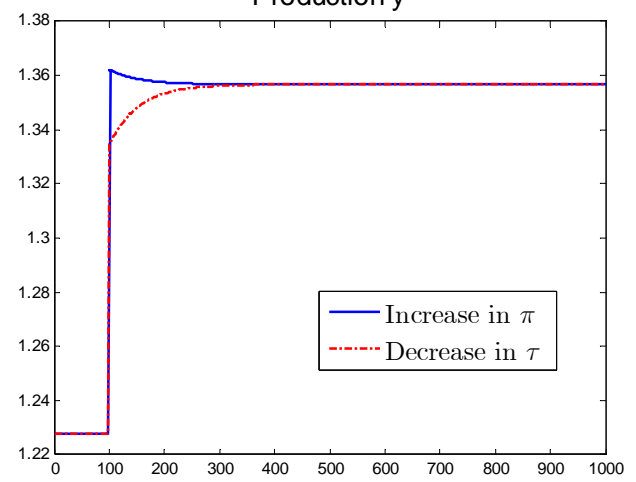

Figure 6: Effect of TFP on capital outflows - Riskless versus portfolio approach External bond holdings $b$

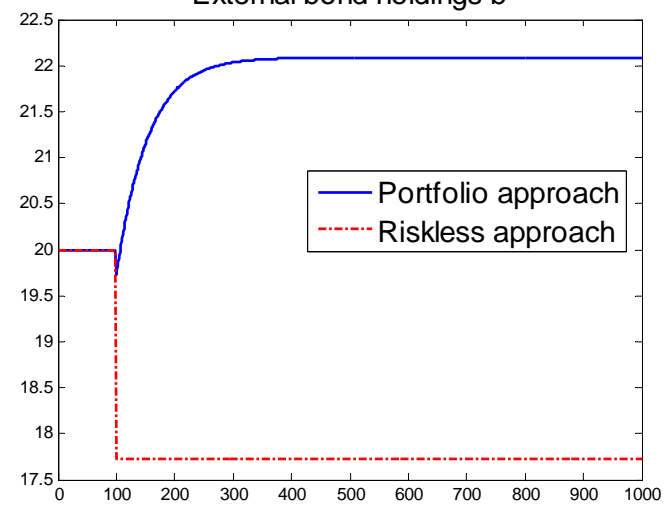


Figure 7: Observed and predicted capital flows by region
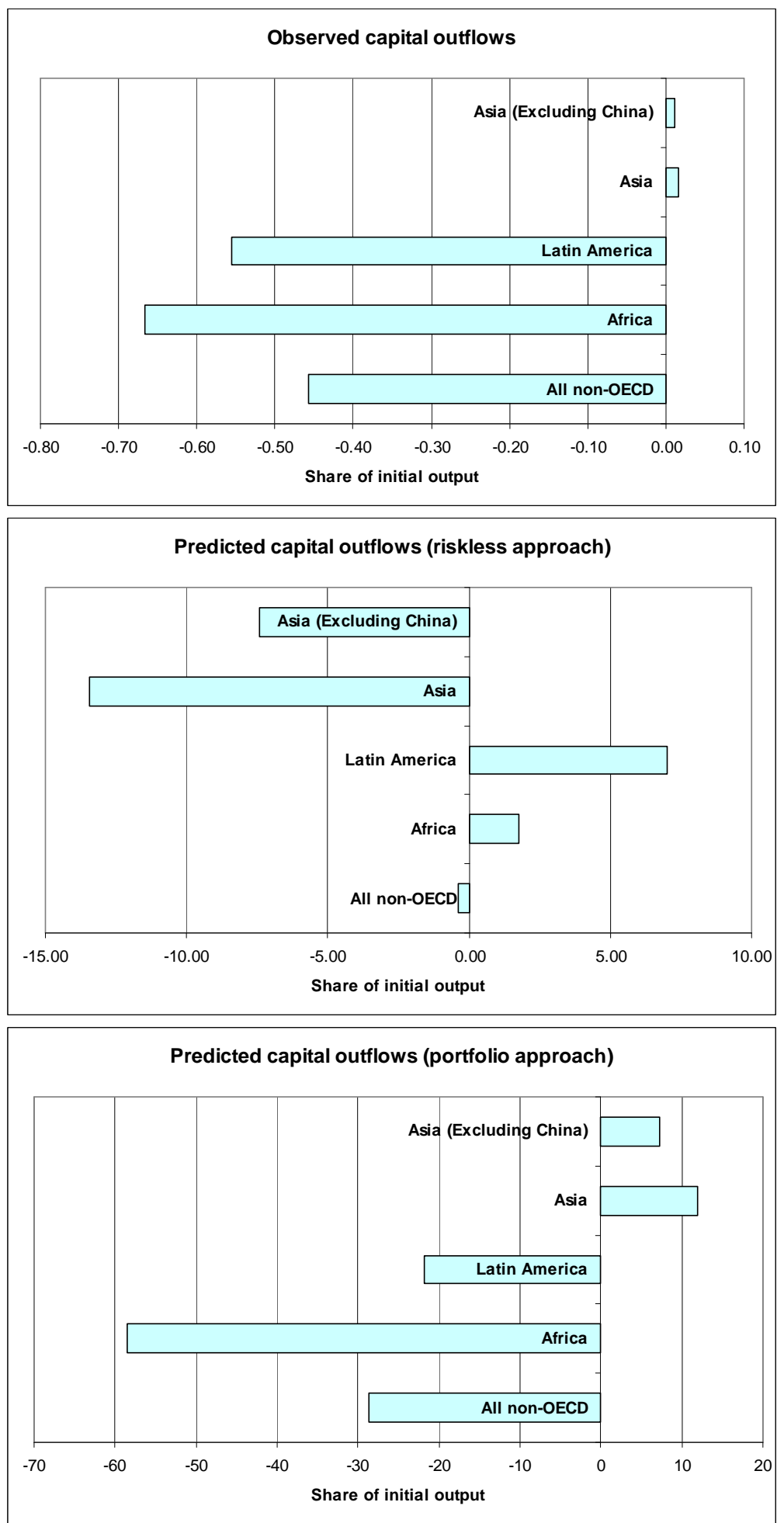

Source: Penn World Tables 6.2 (Heston et al., 2006), Lane and Milesi-Ferretti (2006), author's calculations.

Observed capital flows are the observed ratio of net capital outflows to initial output, predicted capital flows in the riskless and portfolio approaches are respectively $\frac{\Delta B^{R}}{Y_{0}}$ as defined by Equation (13) and $\frac{\Delta B^{P}}{Y_{0}}$ as given by Equation (12).

The figures are unweighted country averages.

Non-OECD countries include also Korea, Mexico and Turkey. 
Figure 8: Actual capital outflows (as a share of initial GDP) against their predicted value, according to the riskless approach, 1980-2003

(a) Whole sample

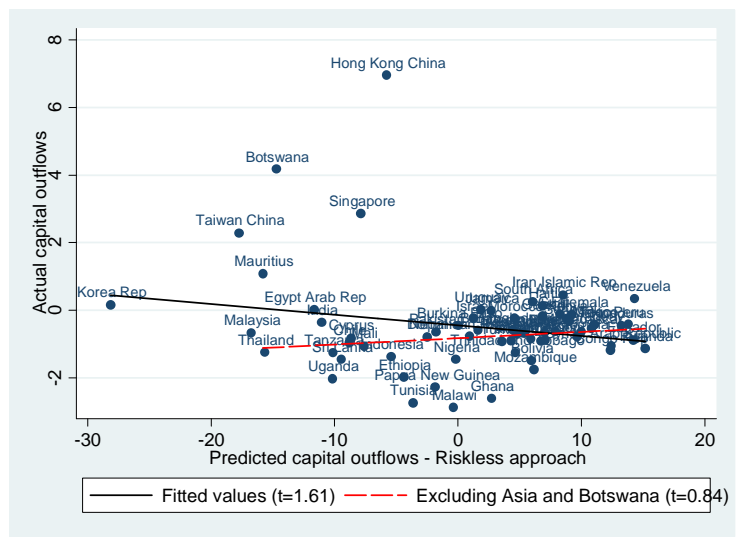

(b) Excluding positive NFA

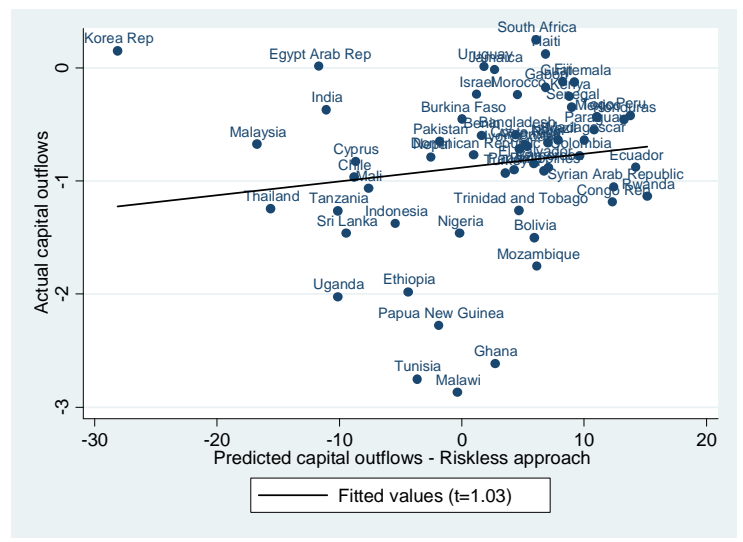

Source: Penn World Tables 6.2 (Heston et al., 2006), Lane and Milesi-Ferretti (2006), author's calculations.

Note: China is excluded.

Figure 9: Actual capital outflows (as a share of initial GDP) against their predicted value, according to the portfolio approach, 1980-2003

(a) Whole sample

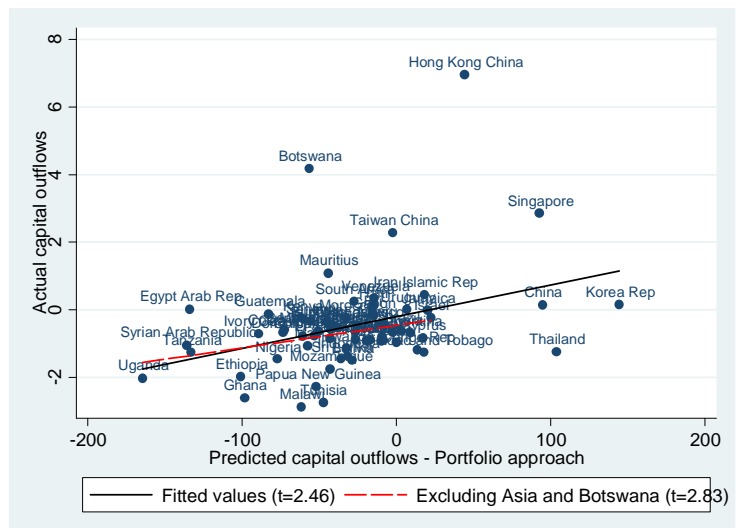

(b) Excluding positive NFA

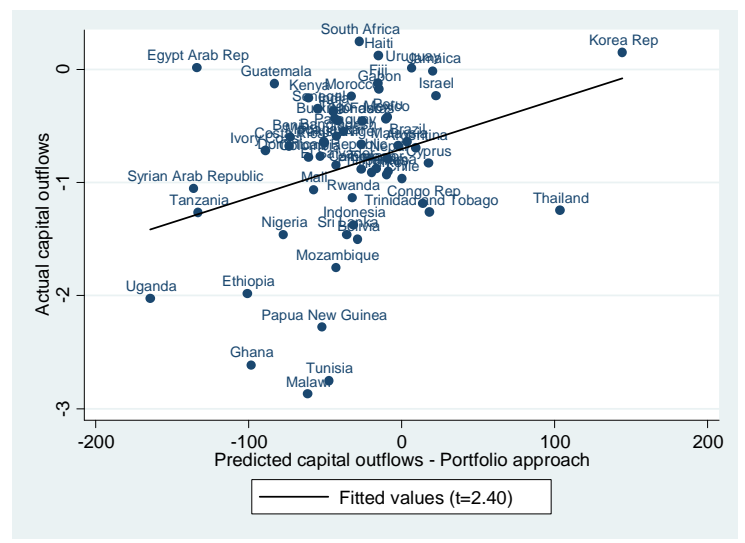

Source: Penn World Tables 6.2 (Heston et al., 2006), Lane and Milesi-Ferretti (2006), author's calculations. 
Figure 10: Actual capital outflows (as a share of initial GDP) against their predicted value, according to the portfolio approach, 1980-2003 - Role of $\tau$

(a)

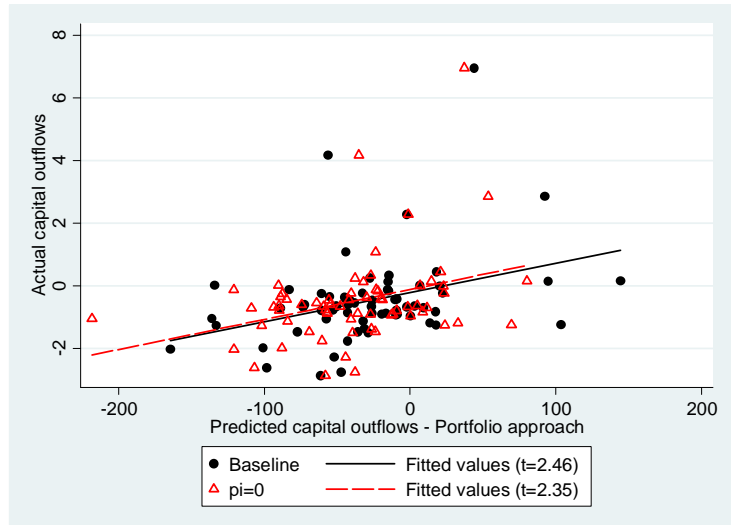

(b)

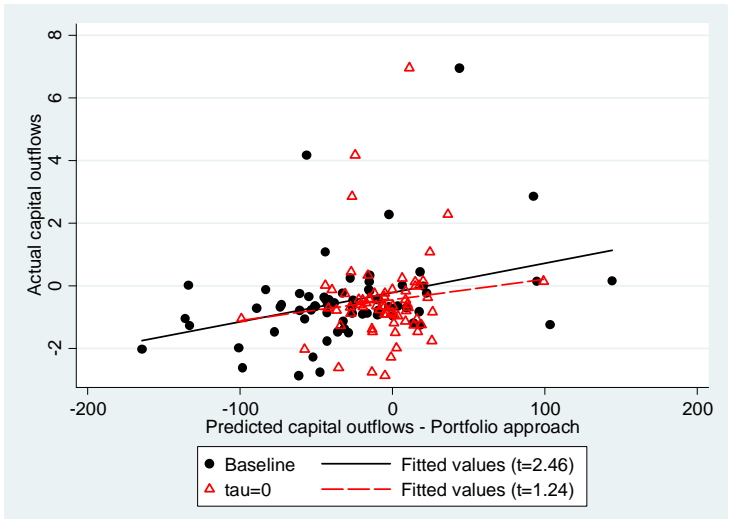

Source: Penn World Tables 6.2 (Heston et al., 2006), Lane and Milesi-Ferretti (2006), author's calculations.

Figure 11: Actual capital outflows (as a share of initial GDP) against their predicted value, according to the portfolio approach, 1980-2003 - Sensitivity to alternative values of risk

(a)

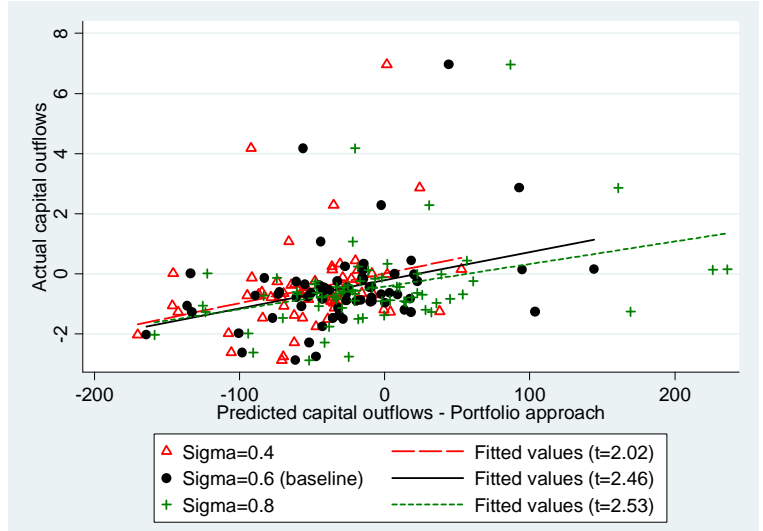

(b)

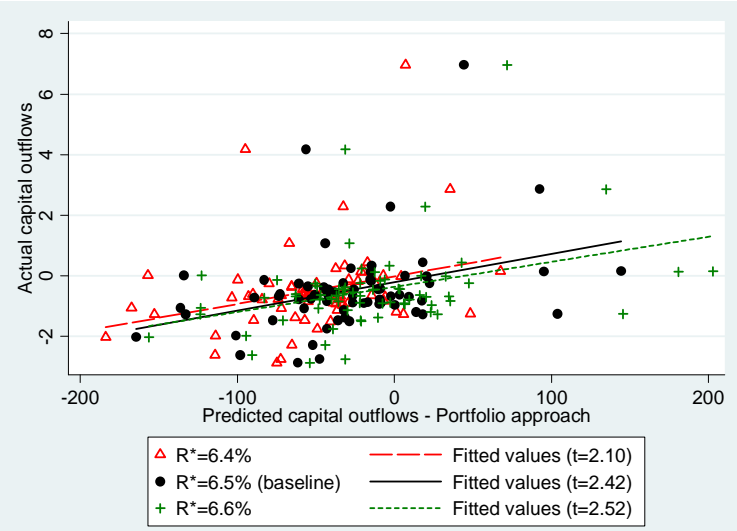

Source: Penn World Tables 6.2 (Heston et al., 2006), Lane and Milesi-Ferretti (2006), Bernanke and Gurkaynak (2001), author's calculations. 